Der Medizinischen Fakultät der Georg-August-Universität eingereicht von Prof. Dr. med. M. Dobbelstein

\title{
Investigation of genetic and translational effects of tumor suppressor proteins in two hereditary forms of renal cell carcinoma
}

\author{
INAUGURAL-DISSERTATION \\ zur Erlangung des Doktorgrades \\ der Medizinischen Fakultät der \\ Georg-August-Universität zu Göttingen
}

vorgelegt von

Katja Nina Maria Dinkelborg aus Berlin 
Die vorliegende Dissertation wurde im Center for Cancer Research, Massachusetts General Hospital, Harvard Medical School, Boston, MA im Zeitraum von Juli 2016 bis Juli 2017 unter der Betreuung von Prof. Dr. Othon Iliopoulos angefertigt.

Dekan:

Prof. Dr. med. W. Brück

\section{Betreuungsausschuss}

Betreuer:

Prof. Dr. med. M. Dobbelstein

Ko-Betreuerin:

Prof. Dr. med. D. Katschinski

\section{Prüfungskommission}

Referent/in

Prof. Dr. med. M. Dobbelstein

Ko-Referent/in:

Drittreferent/in:

Datum der mündlichen Prüfung: 
Hiermit erkläre ich, die Dissertation mit dem Titel " Investigation of genetic and translational effects of tumor suppressor proteins in two hereditary forms of renal cell carcinoma" eigenständig angefertigt und keine anderen als die von mir angegebenen Quellen und Hilfsmittel verwendet zu haben.

Göttingen, den

(Unterschrift) 
Die Daten, auf denen die vorliegende Arbeit basiert, wurden teilweise publiziert:

Schneider M, Dinkelborg K, Xiao X, Chan-Smutko G, Hruska K, Huang D, Sagar P, Harisinghani M, Iliopoulos O (2018): Early onset renal cell carcinoma in an adolescent girl with germline FLCN exon 5 deletion. Fam Cancer 17, 135-139

Wang X, Ahn J, Fiejtek DK, Lin L, Dinkelborg K, Sundaram R, Zheng S, Iliopoulos O, Hodgetts KJ (2019): Synthesis of the HIF-2 $\alpha$ translation inhibitor compound 76 via a JappKlingemann coupling. Tetrahedron Lett $\underline{60}$, 983-985 


\section{Table of Contents}

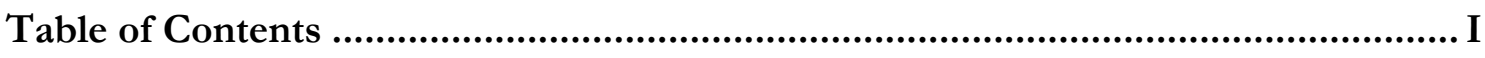

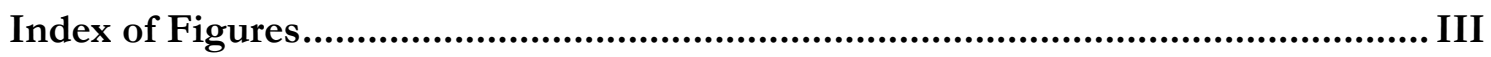

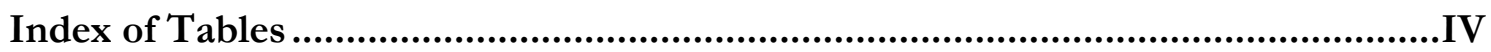

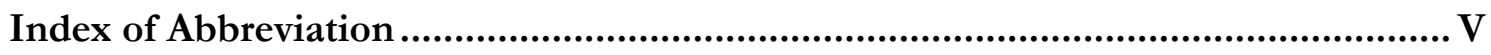

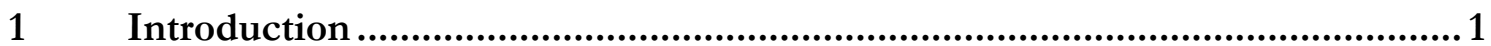

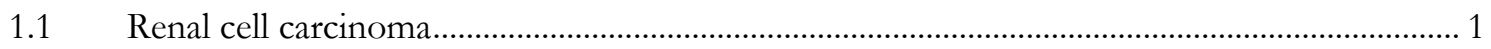

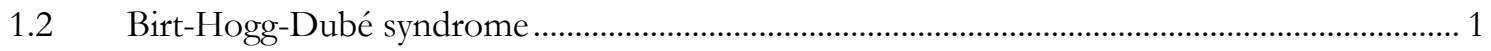

1.2.1 The tumor suppressor protein folliculin ............................................................................... 2

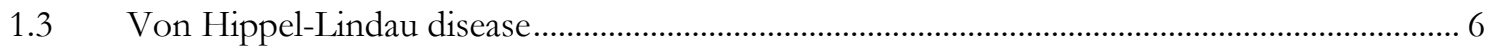

1.3.1 Clear cell renal cell carcinoma and hypoxia metabolism ............................................................ 7

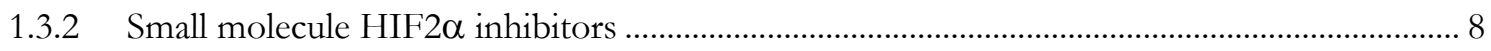

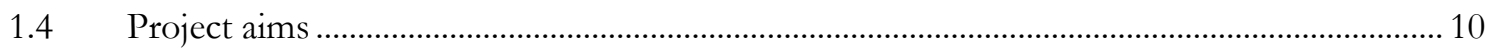

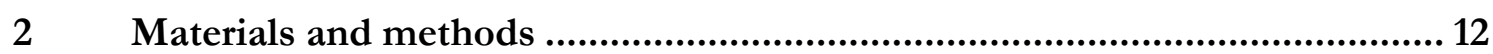

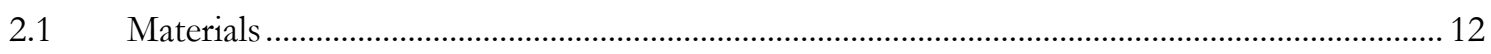

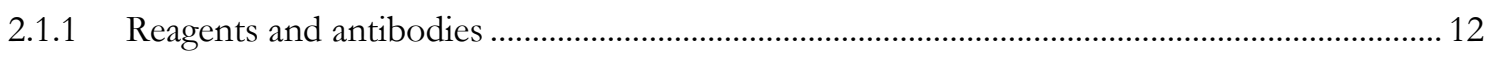

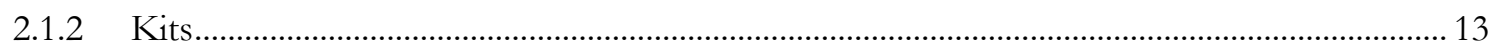

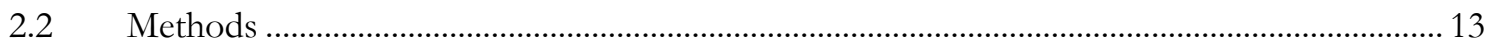

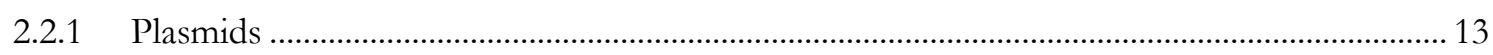

2.2.2 Retrovirus production and transduction of cells ................................................................ 15

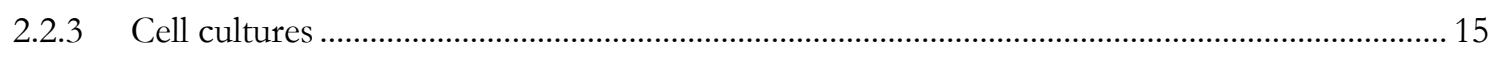

2.2.4 Incubation of cell cultures with HIF inhibitors ................................................................. 15

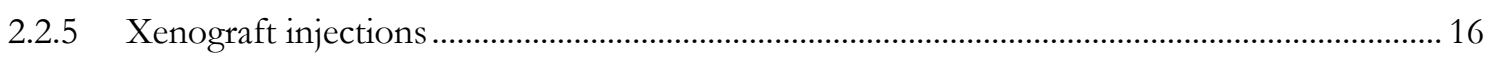

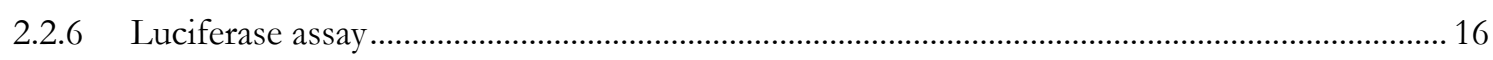

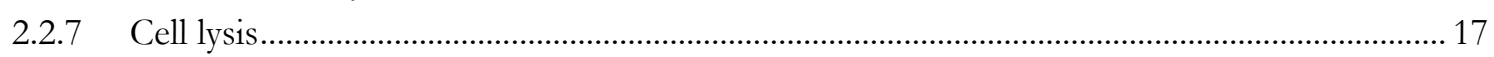

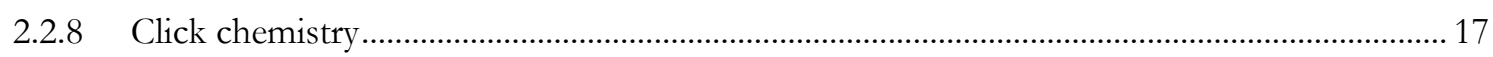

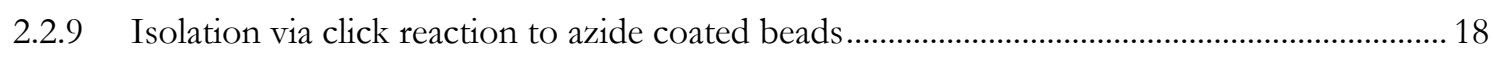

2.2.10 Immunoprecipitation and protein isolation via streptavidin ..................................................... 19

2.2.11 Sodium dodecyl sulfate polyacrylamide gel electrophoresis (SDS-PAGE) .............................. 19

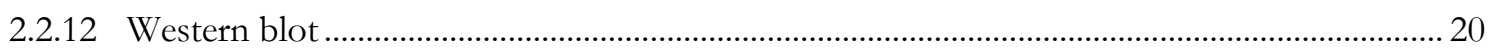

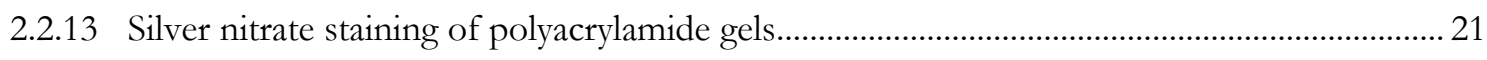

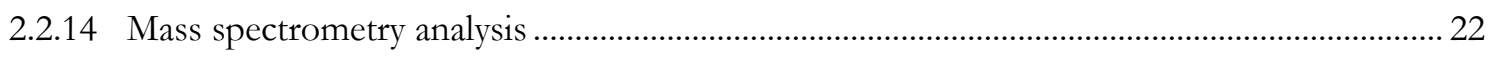

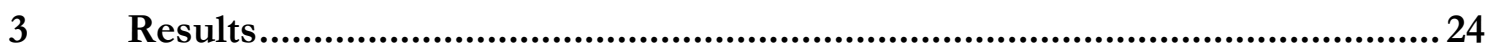

3.1 A novel FLCN mutation promoting tumor growth in vivo ...................................................... 24

3.1.1 "Early onset renal cell carcinoma in an adolescent girl with germline FLCN exon 5 deletion" (Schneider et al. 2018) ................................................................................................ 24 
3.1.2 FLCN germline intragenic deletion encodes a stable protein when reintroduced in

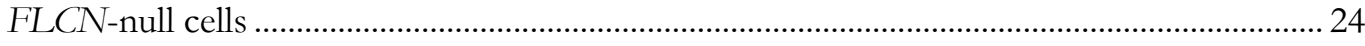

3.1.3 In vivo assay shows loss of tumor growth suppression by FLCN mutant................................2 25

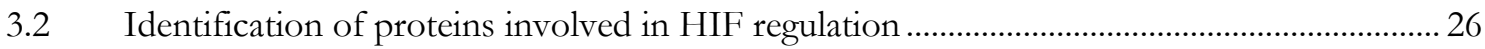

3.2.1 Compound 83 can be modified by click-chemistry and is active ...........................................26

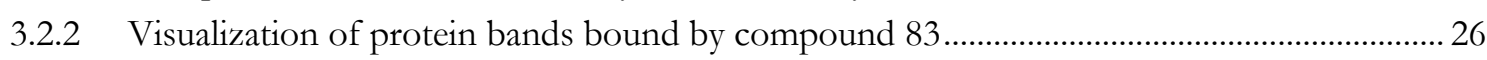

3.2.3 Isolation of cellular proteins interacting with HIF2 $\alpha$ inhibitors............................................ 28

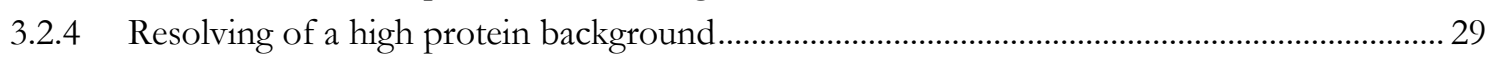

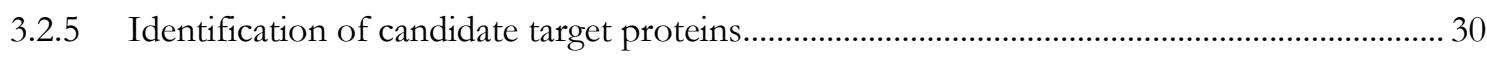

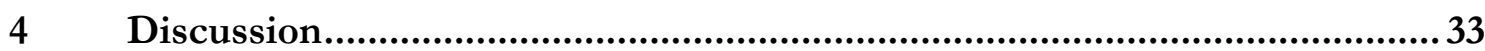

4.1 Can we predict whether a novel FLCN mutation leads to loss-of-function and therefore to be tumorigenic in BHD syndrome?

4.2 Can specific target proteins be identified that bind to the small molecules generated by cell-based high throughput screen?.

4.2.1 Generation of specific small molecule analogs that are substrates for click chemistry

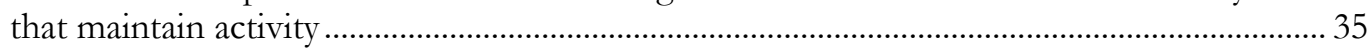

4.2.2 Development and optimization of pull-down techniques to purify candidate proteins ........ 36

4.2.3 Identification of candidate proteins that bind small molecule inhibitors .................................. 37

5 Summary 


\section{Index of Figures}

Figure 1: "Molecular pathways and cellular processes in which FLCN may have a functional role." Figure and text from Schmidt and Linehan 2018 with kind permission of Elsevier

Figure 2: "General Architecture of the FLCN-FNIP2-Rag-Ragulator Supercomplex" Figure and text from Shen et al. 2019

Figure 3: Hypoxia inducible factors in (a) normoxic and (b) hypoxic cells ............................................ 7

Figure 4: Luciferase reporters and synthesis of Compound 76........................................................ 9

Figure 5: Schematic of PCRs creating the patients FLCN mutation p.Gly84_Glu-132del as insert for a plasmid. 14

Figure 6: Copper-catalyzed azide-alkyne cycloaddition (Georgia Tech 2015) 18

Figure 7: "Patient's germline in-frame mutation inactivates FLCN tumor suppressor gene." (Schneider et al. 2018) 25

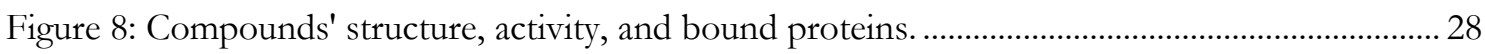

Figure 9: Isolation of the compounds and bound proteins by a streptavidin pull-down assay.......... 29

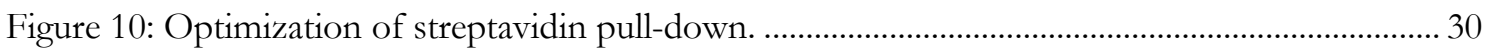

Figure 11: Identification of candidate target proteins......................................................................... 32

Figure 12: Cryo-EM structure of FLCN-FNIP2-Rag-Ragulator complex from Protein Data Bank 6ULG. 


\section{Index of Tables}

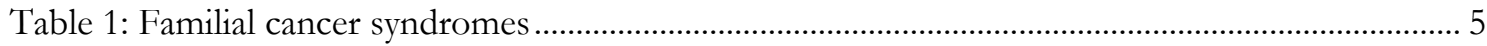

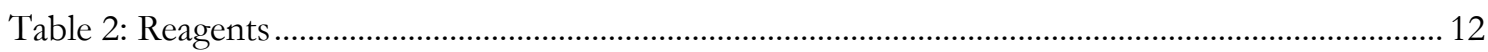

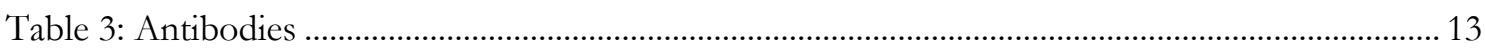

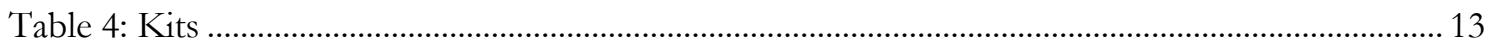

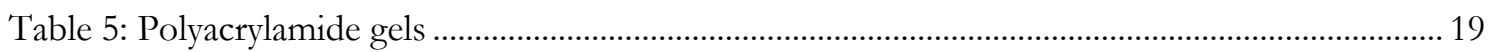




\section{Index of Abbreviation}

AMPK Adenosine monophosphate-activated protein kinase

ATCC American type culture collection

BHD

Birt-Hogg-Dubé

BSA

Bovine serum albumin

ccRCC

Clear cell renal cell carcinoma

DENN

Differentially expressed in neoplastic versus normal cells

DMEM

Dulbecco's modified eagle medium

DMSO

Dimethyl sulfoxide

DNA

Deoxyribonucleic acid

DTT

Dithiothreitol

EDTA

Ethylenediaminetetraacetate

FBS

Fetal bovine serum

FLCN

Folliculin

FNIP

Folliculin interacting protein

GDP

Guanosine diphosphate

GTP

Guanosine triphosphate

GTPase

Guanosine triphosphatase

HEPES

4-(2-hydroxyethyl)-1-piperazineethanesulfonic acid

HIF

Hypoxia inducible factor

HLRCC

Hereditary leiomyomatosis and renal cell carcinoma

HPRC-1

Hereditary papillary renal carcinoma type 1

HRE

Hypoxia responsive element

HRP

Horseradish peroxidase

mRNA

Messenger ribonucleic acid

mTOR

Mammalian target of rapamycin

NP-40

Nonidet P-40

PAGE

Polyacrylamide gel electrophoresis

PBS

Phosphate buffered saline

PHD

Prolyl-hydroxylase domain enzymes

PVDF

Polyvinylidene fluoride

$\mathrm{RCC}$

Renal cell carcinoma

SDS

Sodium dodecyl sulfate

SV40

Simian virus 40

TBS

Tris buffered saline

TBS-T

Tris buffered saline with $0.5 \%$ Tween 20

Tris

Tris(hydroxymethyl) aminomethane

VEGF

Vascular endothelial growth factor

VHL

Von Hippel-Lindau

WT

Wildtype 


\section{Introduction}

\subsection{Renal cell carcinoma}

Renal cell carcinoma (RCC) is the fifth most common cancer in Europe (Ferlay et al. 2018). In 2019 more than 73,000 new cases and 14,000 deaths were estimated in the United States of America (Siegel et al. 2019). RCC is a heterogeneous disease; 75\% of RCC are of clear cell histology, 5\% are papillary (each for type 1 and type 2 disease), the rest chromophobe, oncocytoma or other rare histologic types (Muglia and Prando 2015). RCC is also heterogenous at the molecular level and each histologic type of the disease corresponds to a different cluster of underlying mutations. The majority of RCC present as sporadic disease (not due to germline mutations). An estimated 5-10\% of RCC are manifestations of inherited diseases. There are several familial cancer syndromes caused by germ line mutations of different genes associated with RCC. It is important to identify patients with inherited tumor syndromes because the resulting patient surveillance can lead to early diagnosis of RCC and thus a better outcome. In addition, genetic and biochemical studies that gain insight into the mechanism of inherited diseases predisposing to RCC do inform the abnormalities underlying the sporadic tumors and therefore can lead to the design of rational treatments (Schmidt and Linehan 2016). This thesis studies two different inherited cancer syndromes Birt-Hogg-Dubé (BHD) and von Hippel-Lindau (VHL) disease, looking for a better understanding of the genetics and pathways dysregulated in these diseases. The work presented in this thesis is part of bigger projects established in the Iliopoulos Laboratory at Massachusetts General Hospital and Harvard Medical School.

\subsection{Birt-Hogg-Dubé syndrome}

The BHD syndrome was first described in 1977 by Arthur R. Birt, Georgina R. Hogg and William J. Dubé as "Hereditary fibrofolliculomas with trichodiscomas and acrochordons". In 2002 the syndrome was linked to a germline mutation of the tumor suppressor gene folliculin (FLCN) (Nickerson et al. 2002). Patients are characterized by developing benign skin lesions (fibrofolliculomas or trichodiscomas), spontaneous pneumothoraxes caused by lung cysts and the development of renal cell carcinomas.

The discovery of FLCN mutations as the cause of BHD disease provides the opportunity to test patients for germline mutations. Most BHD patients develop multiple RCC lesions during their lifetime. Those can be treated and cured by surgery if detected at early stage. The challenge is to preserve normal renal parenchyma, and therefore protect kidney function despite repeated procedures to remove RCC. Early and regular abdominal imaging allows the detection of RCC lesions when they are still small. At this stage, the lesions can be 
removed through surgeries, taking away the least kidney parenchyma possible (nephronsparing surgery). BHD diagnosis through genetic testing and regular patient surveillance allows to detect local lesions early which is crucial for kidney preservation and patient outcome (Stamatakis et al. 2013). Regular abdominal imaging of BHD patients was recommended to start at the age of 20 (Jensen et al. 2017), a concept that is now challenged by an early onset BHD case report presented in my thesis.

Patients with BHD disease are at a lifetime risk of developing RCC (of variable histology), pneumothorax, lung cysts, and fibrofolliculomas or trichodiscomas of the skin. The type of BHD-associated lesions, their age of onset and their overall severity differs from patient to patient. Patients that develop spontaneous pneumothorax and/or fibrofolliculomas should be referred for genetic counseling and testing of germline BHD mutations. Algorithms for BHD diagnosis are still developing and improving continuously based on patient data.

\subsubsection{The tumor suppressor protein folliculin}

Nickerson et alii (et al.; 2002) cloned the FLCN tumor suppressor gene by linkage analysis of BHD families. FLCN localizes to chromosome 17p11.2 and encodes the $64 \mathrm{kDa}$ FLCN protein. The gene was named after the benign skin lesions of BHD patients, fibrofolliculomas. The FLCN gene consists of 14 exons and spans a $20 \mathrm{kB}$ of genomic deoxyribonucleic acid (DNA) space. Nickerson et al. reported that the FLCN gene is mutated at the germline of affected families.

Genetic and experimental evidence suggest that FLCN acts as a tumor suppressor gene. Most of the mutations predict for a truncated form of FLCN protein or are small intragenic deletions, but single base substitutions, duplications, and insertions have also been reported (Lim et al. 2010). The second, wild type (W'T) allele, of FLCN is inactivated in the BHDrelated RCC by an independent second inactivating mutation or deletion (loss of heterozygosity) (Vocke et al. 2005). These findings conform to Knudson's “two hit hypothesis" and suggest that FLCN is a tumor suppressor gene (Knudson 1971).

The genetic evidence that FLCN acts as a tumor suppressor gene is corroborated experimentally, using a mouse xenograft assay. FLCN -/- cells injected into the flanks of immunocompromised nude mice grow xenografts whereas the same cells, with WT FLCN reintroduced do not form tumors. Laura Laviolette previously used this in vivo assay in the Iliopoulos Laboratory (Laviolette et al. 2017).

Since the identification of FLCN many hypotheses for its function and potential pathways regulated by FLCN have been put forward. However, the pathways dysregulated through mutations of FLCN leading to the development of BHD disease are still to be determined. 


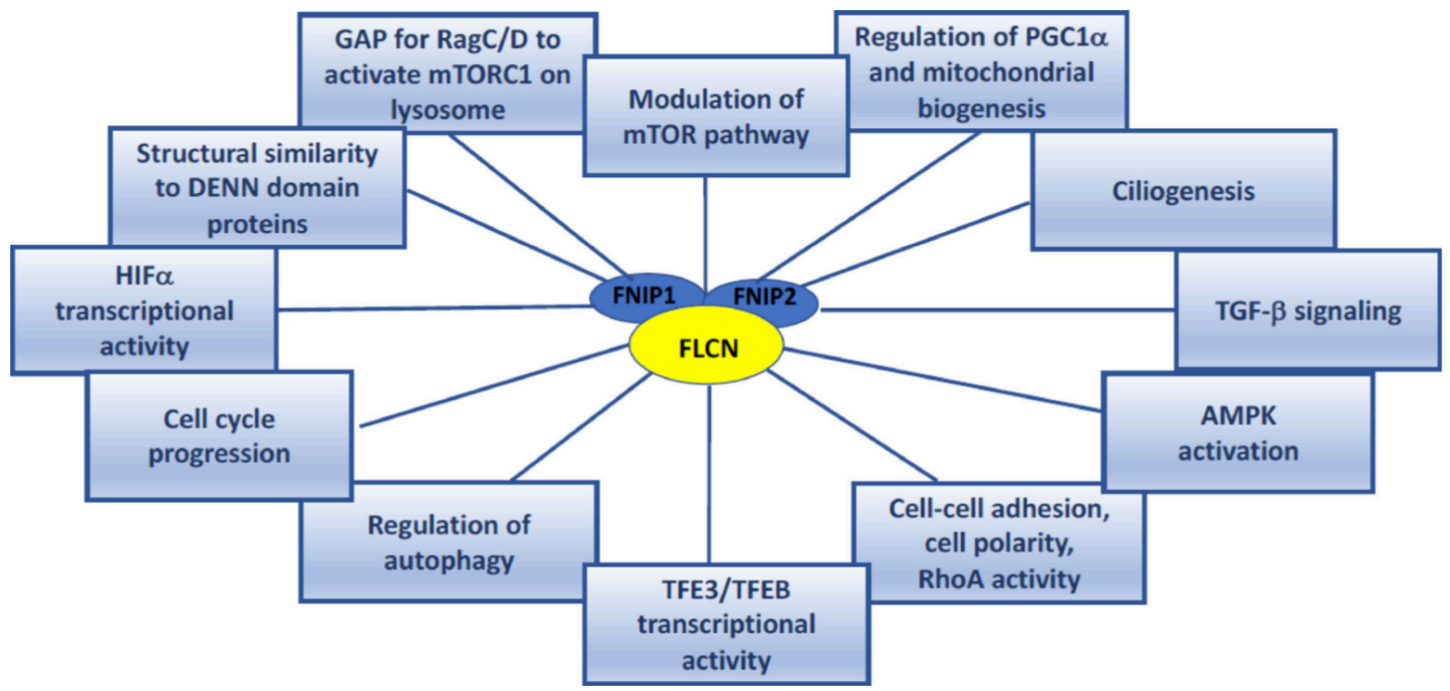

Figure 1: "Molecular pathways and cellular processes in which FLCN may have a functional role." Figure and text from Schmidt and Linehan 2018 with kind permission of Elsevier

Two FLCN interacting proteins (FNIP 1 and 2) have been identified. Both showed binding of FLCN through its c-terminus and also interacted with AMP-activated protein kinase (AMPK). This interaction suggests a possible role of FLCN in modulating energy and nutrient sensing of the cell and might interact with the AMPK/mTOR axis (Baba et al. 2006; Hasumi et al. 2008). The mammalian Target of Rapamycin (mTOR) is a serine/threonine kinase and part of the multiprotein complex mTOR 1 regulating cell growth, mRNA translation, and other oncogenic pathways that are upregulated in many cancers (Guertin and Sabatini 2007). This interaction of FLCN has led to clinical trials with mTOR inhibitors for BHD associated kidney cancers (Benusiglio et al. 2014).

However, other findings have indicated that FLCN also plays a role in the activation of mTOR complex 1 (mTORC1), by enabling its localization to the lysosomal membrane. Here, it binds to heterodimers consisting of $\mathrm{RagA}$ or $\mathrm{B}$ and $\mathrm{RagC}$ or $\mathrm{D}$, depending on their nucleotide loading state, which is regulated by upstream sensors (Kim et al. 2008). The GTPase heterodimer binds mTORC1 when RagA/B binds guanosine triphosphate (GTP) and RagC/D binds guanosine diphosphate (GDP) (Tsun et al. 2013). There are different regulators of the nucleotide loading state of the Rag GTPases that ensure mTORC1 activity responds to nutrient levels in the cell correctly.

One of those regulators is the complex of FLCN and FNIP2, which has been identified to stimulate GTP hydrolysis of RagC/D to GDP, enabling mTORC1 activation (Petit et al. 2013; Tsun et al. 2013). Recently the structure of the FCLN/FNIP2 RagA/RagC complex has been solved at a 3.6 Angstrom resolution (Lawrence et al. 2019). This complex form when the cell is under amino acid starvation, FLCN/FNIP2 then lose the GTPase activating function towards RagC/D and mTORC1 is inactive. Lawrence et al. (2019) discovered a displacement of a catalytically required arginine (arginine 164) in FLCN leading to the loss of this function. In addition, Shen et al. (2019) investigated the structure through 
cryoelectron microscopy analysis (Figure 2a) and identified the same arginine as the catalytic arginine finger for the GTPase activating function.

A

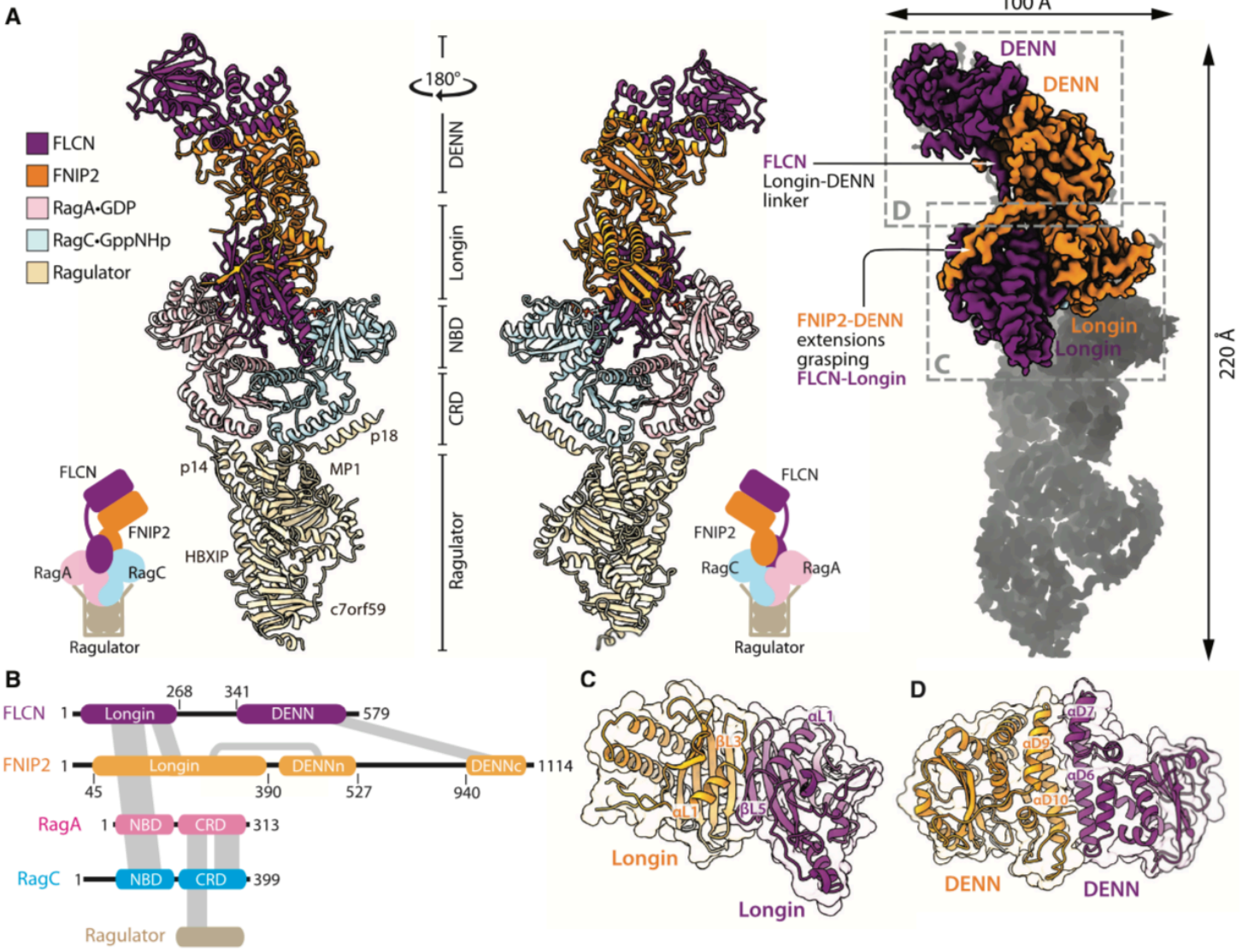

Figure 2: "General Architecture of the FLCN-FNIP2-Rag-Ragulator Supercomplex" Figure and text from Shen et al. 2019

a Atomic model, cartoon model, and domain assignment for the FLCN-FNIP2-Rag-Ragulator nonamer. Subunits of the FLCN-FNIP2-Rag-Ragulator complex are colored as following: purple, FLCN; orange, FNIP2; pink, RagA; cyan, RagC; brown, Ragulator.

b Domain arrangement for the FLCN-FNIP2-Rag-Ragulator supercomplex. Inter- and intrasubunit interactions are shown by gray bars between domains. The DENN domain within FNIP2 is split in two, denoted as DENNn (DENN domain N-terminal fragment) and DENNc (DENN domain C-terminal fragment).

c Structural model for the Longin domain heterodimer within the FLCN-FNIP2 complex.

d Structural model for the DENN domain heterodimer within the FLCN-FNIP2 complex. With kind permission of Cell Press

Shen et al. (2019) also investigated the interaction between FLCN and FNIP2 closer and identified that the heterodimer is stabilized through two DENN (differentially expressed in neoplastic versus normal cells) domains of the $C$ termini of each protein and two Longin domains of the $\mathrm{N}$ termini of both proteins. The Longin domain heterodimer localizes between both nucleotide binding domains of RagA and Rag C in the complex (Figure 2 a and c). This structure was interpreted to be an on-pathway intermediate to GTP hydrolysis and further investigation is needed to understand how it translates amino acid signals toward 
mTORC1. Interestingly, these findings suggest a new FLCN function, that is carried out mainly by the $\mathrm{N}$ terminal region of the protein. However, most studies so far suggested the FLCN c-terminal region as necessary for its function and interestingly, most BHD associated FLCN mutations predict for a truncated protein (Lim et al. 2010).

Other familial cancer syndromes (Table 1) associated with RCC e.g. Von Hippel-Lindau (VHL), hereditary papillary renal carcinoma type 1 (HPRC-1), hereditary leiomyomatosis and renal cell carcinoma (HLRCC) predispose patients to RCC of one specific histology and are not linked to FLCN mutations. VHL is caused by germline mutation of the VHL gene and predisposes patients to exclusively clear cell RCC and other hyper vascular tumors. HPRC1 is caused by mutations of c-met. HPRC-1 patients predominantly develop type 1 papillary renal carcinomas that show papillary or tubulopapillary histologies (Lubensky et al. 1999). HLRCC is caused by germline mutations of fumarate hydratase and leads to the development of type 2 papillary renal cancers along with cutaneous and uterine leiomyomas (Menko et al. 2014).

In contrast to other RCC tumor suppressor genes, FLCN associated RCC can occur as any histologic type and even in hybrid forms with features of more than one histological type. RCC tumors in BHD patients may be chromophobe, oncocytic, hybrid forms of chromophobe with oncocytic, clear cell, papillary or even non-classifiable RCC (Pavlovich et al. 2002). Frequencies of the different types vary from study to study but hybrid tumors containing chromophobe and oncocytic histological subtypes are among the most frequent in BHD.

Table 1: Familial cancer syndromes

\begin{tabular}{llll} 
& \multicolumn{3}{c}{ Familial cancer syndromes } \\
syndrome & Mutated gene & Signaling pathway/target & RCC subtype \\
\hline VHL & VHL & HIF2 $\alpha$ & Clear cell type \\
BHD & FLCN & unknown & multiple \\
HPRC-1 & c-met & Receptor tyrosine kinase & Type 1 papillary \\
HLRCC & Fumarate bydratase & Tricarboxylic acid cycle & Type 2 papillary
\end{tabular}

There are no known phenotype-genotype correlations in BHD disease. Although there have been statistical observations of more lung cysts and spontaneous pneumothoraxes in BHD patients with exon 9 and 12 mutations (Toro et al. 2008). The type of germline mutation seems not to inform about penetrance, expressivity or aggressiveness of the disease. No correlation between germline mutations and histologic type of RCC has been identified. Over time, as the number of detected FLCN mutations will increase, it is possible that such 
correlations will be established, and the type of germline mutation will inform the clinical course of the disease and therefore shape our strategies for prevention and/or early detection of RCC and other BHD-related lesions.

\subsection{Von Hippel-Lindau disease}

In the early 20th century both Eugen von Hippel and Arvid Lindau described patients with angiomas (highly vascularized tumors) in the retina and central nervous system (von Hippel 1904; Lindau 1927). Later it was discovered that these angiomas were caused by a germline mutation of the von Hippel-Lindau (VHL) gene located on chromosome 3p25 (McKusick and Amberger 1993). The familial disease caused by this mutation along with the gene are now named after their first describers, von Hippel and Lindau.

Patients with a germline mutation in the VHL gene are predisposed to the development of highly vascularized benign and malignant tumors throughout their lifetime. The most common of these are clear cell renal cell carcinoma (ccRCC), hemangioblastomas of the central nervous system including the retina, pheochromocytoma, and paragangliomas, neuroendocrine tumors of the pancreas and serous cystadenomas of the middle ear, pancreas, epididymis, and adnexal organs. In these tumors the remaining WT VHL allele is inactivated by somatic mutation or deletion. In keeping with the Knudson hypothesis, 90\% of sporadic ccRCC harbor a bi-allelic inactivation of the VHL gene (Cancer Genome Atlas Research Network 2013).

The VHL protein serves as the substrate-binding subunit of an E3 ubiquitin ligase complex (Lisztwan et al. 1999). Here, the VHL protein plays an important role in the regulation of hypoxia metabolism by binding to the alpha subunits of hypoxia inducible factors $1 \alpha$ or $2 \alpha$ (HIF-1 $\alpha$, HIF2 $\alpha$ also known as EPAS) and targeting it for proteasomal destruction. At normal oxygen concentrations in the cells, prolyl-hydroxylase domain enzymes (PHD 1-3, EGLN) mediate the hydroxylation of specific prolyl residues in the HIF- $\alpha$ subunits. These prolyl residues are part of an oxygen dependent degradation domain. VHL recognizes hydroxylated HIF- $\alpha$ and via the E3 ubiquitin ligase complex promotes ubiquitination, which then leads to HIF's proteasomal degradation (Figure 3a, Lisztwan et al. 1999).

In hypoxic cells, HIF- $\alpha$ is not hydroxylated and therefore not recognized by VHL. Stabilized HIF- $\alpha$ subunits dimerize with the constitutively expressed beta subunits (HIF-1 $\beta$ also known as ARNT or HIF2 $\beta$ ) and bind to DNA at regions of specific base pair sequence termed hypoxia responsive elements (HRE). Dimerization and binding of HIF to HRE leads to transactivation of a wide range of genes (Figure 3b, Schödel et al. 2011). Loss-of-function mutations of the VHL gene causes constitutive upregulation of HIF- $\alpha$ and constitutive activity of hypoxia inducible factors (Iliopoulos et al. 1996). The oxygen-dependent HIF regulation fails, and cells appear to be under hypoxia all the time, initiating hypoxic cell metabolism and angiogenesis. Constitutive HIF expression promotes tumor growth by 
turning on several genes that enhance cell proliferation and reshape tumor metabolism (Majmundar et al. 2010).

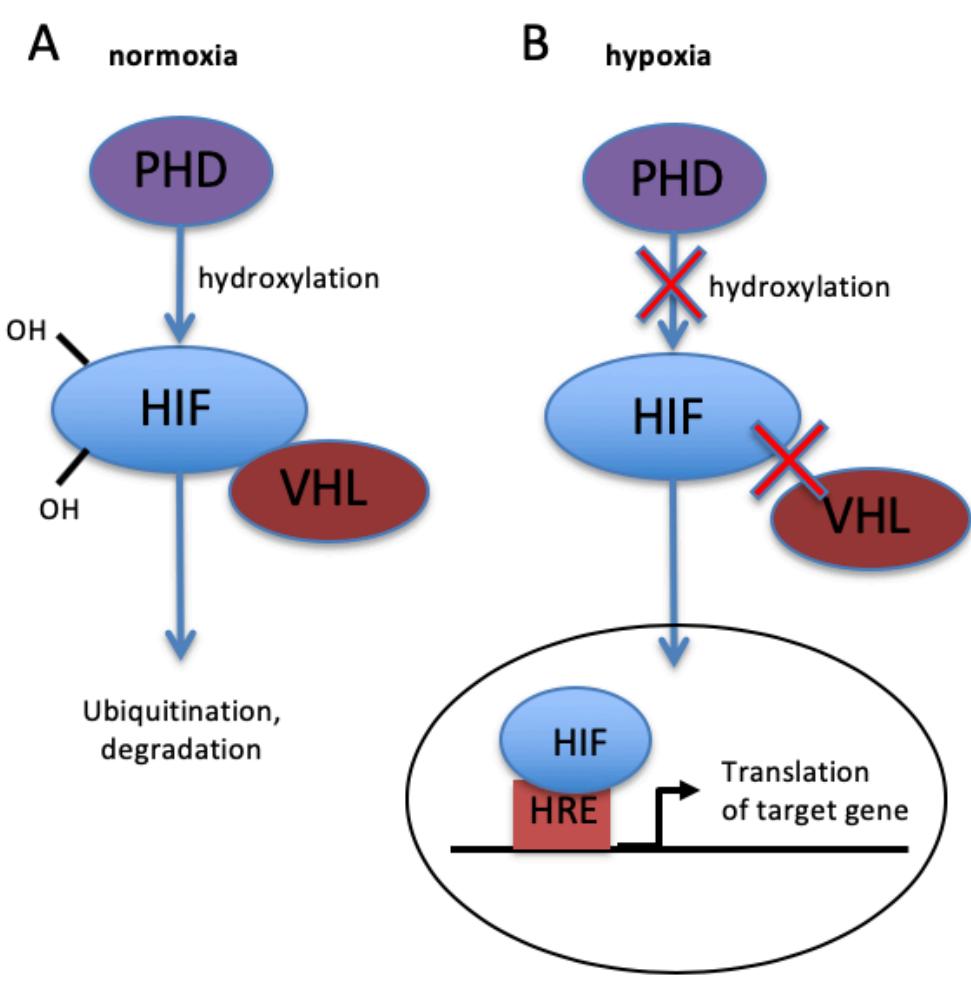

Figure 3: Hypoxia inducible factors in (a) normoxic and (b) hypoxic cells (modified after Aki et al. 2018)

\subsubsection{Clear cell renal cell carcinoma and hypoxia metabolism}

Histopathologically, RCC can be separated into different types, the most prevalent being the highly vascularized ccRCC (50-75\%) (Shuch et al. 2015). As in the familial type of ccRCC also $90 \%$ of the cases of sporadically occurring tumors are characterized by a loss of function of VHL leading to an upregulation of HIF $\alpha$ as stated above (Cancer Genome Atlas Research Network 2013).

There are different isoforms of HIF $\alpha$ that can have both overlapping and distinct functions. The most studied isoforms are HIF1 $\alpha$ and HIF2 $\alpha$. Interestingly, in ccRCC HIF1 $\alpha$ is a potential tumor suppressor protein by inhibiting tumor growth (Shen et al. 2011). Contrary to that, HIF2 $\alpha$ functions as an oncogene in ccRCC and it has been proven necessary and sufficient for the development of VHL-null ccRCC (Kondo et al. 2002; Zimmer et al. 2004; Iliopoulos et al. 1996). These opposing functions can be accounted for by the different set of genes activated by the two HIF paralogs (Schödel et al. 2016).

Upregulation of HIF $2 \alpha$ rewires cancer cell metabolism and activates cancer angiogenesis. This enables the tumor cells to grow faster than the surrounding normal cells. Among the target genes of HIF are the vascular endothelial growth factor (VEGF) and its receptor, 
activating angiogenesis. It also has been shown that HIF $2 \alpha$ activates the known oncogene c-Myc, which promotes tumor proliferation (Gordan et al. 2007). Overall, HIFs play an important role in cancer specific cell changes such as angiogenesis, erythropoiesis, cell proliferation, metabolism and metastasis (Majmundar et al. 2010).

Early stage renal cell cancer can be cured by surgery. However, $20-30 \%$ of the patients are diagnosed at a metastatic stage of the disease and for these patients, therapeutic options are limited (Motzer et al. 1996). Efforts for targeted therapies of ccRCC have focused on targeting HIF2 $\alpha$ or its downstream targets. Drugs inhibiting the product of HIF2 $\alpha$ target genes, such as the VEGF or its cognate receptors showed promising results. However, hypoxia caused by this inhibition again leads to an upregulation of HIFs and other hypoxic pathways are activated making these cells resistant to VEGF inhibition (Pichler and Heidegger 2017).

\subsubsection{Small molecule HIF2 $\alpha$ inhibitors}

The Iliopoulos Laboratory established a cell-based assay to screen for small molecules inhibiting HIF2 $\alpha$ expression in VHL knock out RCC cells (Zimmer et al. 2008). VHL-null cells were stably infected with a luciferase reporter driven by the DNA binding sites of HIF2 $\alpha$, called hypoxia responsive elements (HRE, 7H4 cells, Figure 4a). Binding of HIF2 $\alpha$ to four HREs upstream of the Luciferase coding region drives the translation of Luciferase. When stably introduced into VHL-deficient ccRCC cell lines, the Luciferin signal represents the overall HIF2 $\alpha$ activity in those cells. To control for non-specific suppression of transcriptional activity the library was tested on the same cells stably infected with luciferase reporter driven by a constitutive, HIF-independent, simian virus 40 (SV40) promoter (7SV40 cells, Figure 4a). This assay is described further in the methods section. 
A

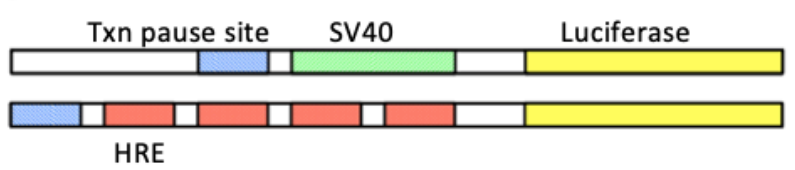

$7 S V 40$

$7 \mathrm{H} 4$

B

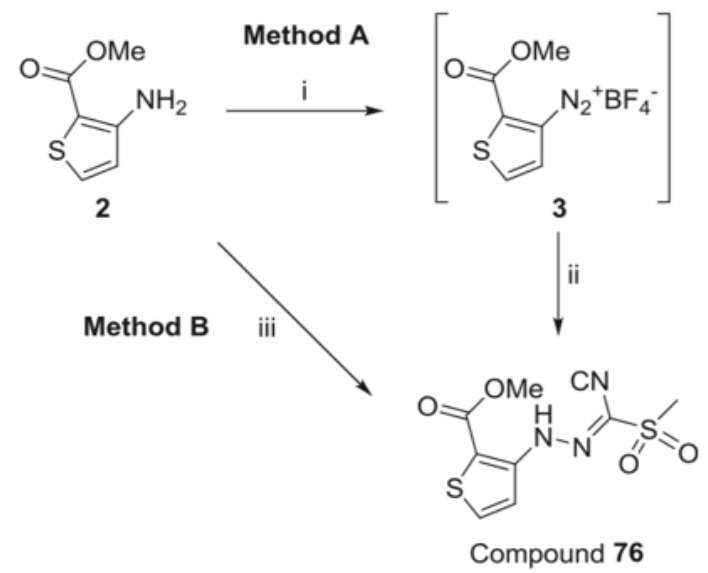

C

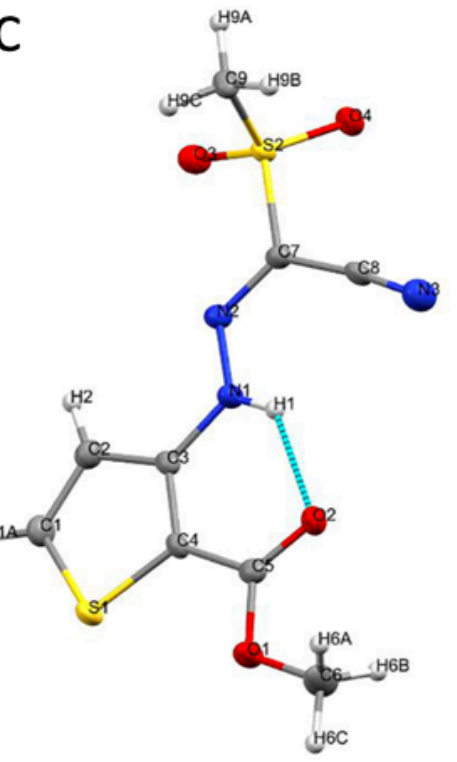

Figure 4: Luciferase reporters and synthesis of Compound 76

A: Schematic of Luciferase reporters for cell based high-throughput screen of small molecule libraries. (Zimmer et al. 2008, with kind permission of Molecular Cell.) B: Two different routes to synthesize compound 76 out of commercially available methyl 3-amino-2-thiophene carboxylate (2).

C: X-ray crystal structure of compound 76. The light blue line represents a hydrogen bonding within the molecule. (b and c: Wang et al. 2019, with kind permission of Tetrahedron Letters)

Using this assay, the Iliopoulos Laboratory performed a high-throughput screen with a total amount of 58,000 compounds to identify small molecule HIF2 $\alpha$ inhibitors. 8 compounds were identified that decrease Luciferase activity in $7 \mathrm{H} 4$ cells by more than $80 \%$ without having an effect on 7SV40 cells. Those findings were then confirmed by testing these compounds in different RCC cell lines (Zimmer et al. 2008).

Electrophoretic mobility shift assays showed that the compounds repressed HIF2 $\alpha$ translation by enhancing the binding of iron regulatory protein 1 (IRP1) to the HIF2 $\alpha$ messenger ribonucleic acid (mRNA). The binding region was identified to be an iron responsive element (IRE) in the 5' untranslated region of the HIF2 $\alpha$ transcript (Sanchez et al. 2007). The HIF1 $\alpha$ transcript does not contain this IRE, which makes the compounds very specific to HIF2 $\alpha$ translation inhibition (Zimmer et al. 2008).

In vivo studies in a VHL knockout zebrafish model showed significant activity of these HIF2 $\alpha$ inhibitors. VHL deficient zebrafish show phenotypes similar to these of VHL patients such as erythrocytosis and blood vessel overgrowth in the brain and retina, similarly to hemangioblastomas in VHL patients. Moreover, epithelial abnormalities in the fish kidney resembled characteristics of early stage ccRCC (Noonan et al. 2016). Treatment of vhl -/zebrafish with compound 76 (Figure 4c), the lead compound of the HIF2 $\alpha$ inhibitors 
showed normalization of these pathologies and improved overall survival in early embryonic stages (Metelo et al. 2015).

Taken together, these findings strongly suggest compound 76 inhibits HIF2 $\alpha$ translation. However, further studies are required to identify how and in what way the compounds interact in the cell and what target proteins they bind to or interact with. A cell-based screen as done by Zimmer et al. (2008) is a great tool to identify compounds modulating one specific phenotype in the cell. However, identification and validation of the target which may be far away from the process one is studying is often difficult.

The derivative compounds presented in this thesis were synthesized by the Laboratory of Drug Discovery in Neurodegeneration of the Brigham and Women's Hospital and Harvard Medical School. The synthesis of compound 76 identified by Zimmer et al. was recently published by this laboratory (Wang et al. 2019). To allow further studies of the compounds' biological properties as well as the structure activity relation, a facile and scalable synthetic route was developed. Two different methods were tested to convert the commercially available methyl 3-amino-2-thiophene carboxylate (Figure 4b \#2) into compound 76. The structure was then confirmed by single crystal X-ray analysis (Figure 4c). This method allows the substitution of the substrate with different arylamines to synthetize analogs of compound 76 for investigation of the structure activity relation (Wang et al. 2019). All newly synthesized compounds can be tested by Luciferase assay and their activity can be compared to compound 76.

\subsection{Project aims}

Gaining a better understanding of the mechanisms underlying specific hereditary cancers may lead to the development of novel therapeutic strategies not only for familial but also for sporadic cancers. In this work two different hereditary cancer diseases associated with RCC were investigated.

Early diagnosis and regular surveillance of BHD patients is crucial to reduce morbidity and mortality. Investigation of possible genotype-phenotype correlation of BHD disease requires identification of FLCN mutations promoting tumor growth in vivo.

HIF $2 \alpha$ is a validated target for treatment of sporadic and inherited ccRCC as well as other HIF2 $\alpha$-driven tumors. Small molecular HIF2 $\alpha$ inhibitors identified by the Iliopoulos Lab show promising characteristics including specificity and efficacy in vitro and in vivo. Further preclinical improvement of HIF $2 \alpha$ inhibitors depends on identification of the direct target of these compounds. In addition, identification of the direct targets may reveal new information about HIF regulation and hypoxia sensing.

My thesis work addresses the following questions: First, can we predict whether a novel FLCN mutation leads to loss-of-function and therefore to be tumorigenic in BHD 
syndrome? We would like to provide proof that a patient derived mutant FLCN can generate a tumorigenic phenotype in an RCC xenograft tumor model.

Second, can the specific target proteins be identified that bind to the small molecules generated by high throughput screen? We will approach this question through the following three steps: 1. Generation of specific small molecule analogs that are substrates for click chemistry and maintain activity. 2. Development and optimization of pull-down techniques to purify candidate proteins. 3. Identification of candidate proteins that bind small molecule inhibitors. 


\section{$2 \quad$ Materials and methods}

\subsection{Materials}

\subsubsection{Reagents and antibodies}

Table 2: Reagents

\section{Reagents}

Reagent Company

30\% Acrylamide: 0.8 Bis-Acrylamide stock National Diagnostics (\#EC-890) solution

Amphopac

Azide Magnetic Beads

Biotin-azide

Dulbecco's phosphate buffered saline (DPBS)

Dynabeads M-280 Streptavidin

Dynabeads Protein A

FBS (fetal bovine serum)

Lipofectamine 2000 transfection reagent

Nonidet P-40

Dulbecco's Penicillin-Streptomycin-

Glutamine

Phosphate Buffered Saline

Polybrene

Ponceau S

Precision Plus Protein Kaleidoscope

Puromycin

$0.25 \%$ Trypsin-EDTA (1X)

VSV-G (vesicular stomatitis virus glycoprotein)
Millipore

Click Chemistry Tools (\#CLK-1036)

Click Chemistry Tools (\#AZ104-25)

Sigma Aldrich (\#D8537)

Invitrogen (\#11205D)

Invitrogen (\#10001D)

Corning (\#35-010-CV)

Invitrogen (\#11668019)

MP Biomedicals (\#MP1RIST1315)

Gibco (\#10378016)

Gibco (\#10010023)

Millipore (\#TR-1003-G)

Sigma-Aldrich \#P3504

Bio Rad (\#1610375)

Sigma-Aldrich (\#P8833)

Gibco (\#25200056)

Millipore 
Table 3: Antibodies

Primary Antibodies for Western Blot

\begin{tabular}{llll} 
Target & Species & Company & Dilution \\
\hline Folliculin & rabbit & Cell Signaling (\#3697) & $1: 10,000$ \\
Aconitase 1 & rabbit & $\begin{array}{l}\text { Gift of Dr. Kostas Pantopoulos (McGill } \\
\text { University, Montreal, Canada). }\end{array}$ & $1: 1,000$ \\
Actin & mouse & Invitrogen (\#MA5-11869) & $1: 30,000$ \\
Peflin & rabbit & Proteintech (\#10151) & $1: 500$ \\
& & Secondary Antibody for Western Blot & \\
Rabbit & goat & Invitrogen (\#G21234) & $1: 10,000$ \\
Mouse & goat & Invitrogen (\#G21040) & $1: 10,000$
\end{tabular}

\subsubsection{Kits}

Table 4: Kits

\section{Kits}

\begin{tabular}{ll} 
Name & Company \\
\hline Bradford assay system & Bio Rad (\#5000006) \\
Luciferase assay system & Promega (\#E1910) \\
Click it protein reaction buffer & Invitrogen (\#C10276) \\
Click-It Protein Enrichment Kit & Invitrogen (\#C10416) \\
Luciferase Assay System & Promega (\#E1910)
\end{tabular}

\subsection{Methods}

\subsubsection{Plasmids}

The plasmids and oligonucleotides used to generate FLCN WT were previously described (Laviolette 2017). FLCN del pG84-E132 was PCRed in three steps. We designed new oligos that included the last 21 bases encoding the 7 amino acids before the glycine, which is the first amino acid that is deleted by the mutation (first 21 bases of OI-2399) and then the first 
19 bases that follow directly after the deletion, encoding the amino acids following the deleted glutamine 132 in the wildtype FLCN mRNA (last 19 bases of OI-2399). OI-2398 is the antisense strand of OI-2399. For all PCRs the Phusion high-fidelity PCR kit (Fisher \#F553S) was used.

The first PCR (Figure 5) was to generate the first part of FLCN up to the deletion. Oligos used were 5'-GCGC GGATCC GCCACC ATG GAT TAC AAA GAT GAT GAT AAA AAT GCC ATC GTG GCT CTC TG-3' (OI-1468, encoding the Bam HI restriction site, the Kozak consensus sequence and the start of the FLCN mRNA) and 5'-C TTC ACG GCC AGG GCA GAC CTC GCA CAT GTC CGA CTT TTT-3' (OI-2398). The second PCR (Figure 5) generates the FLCN part after the deletion, oligos used were 5'-AAA AAG TCG GAC ATG TGC GAG GTC TGC CCT GGC CGT GAA G-3' (OI- 2399) and 5'-GCGC GAATTCA GT'T CCG AGA CTC CGA GGC TGTG-3' (OI-613, encoding the end of the FLCN mRNA and the Eco RI restriction site). Both PCR results were controlled by running them through agarose gels and controlling the product sizes. The correct bands (PCR 1 260basepairs and PCR2 1390basepairs) were then cut out and eluted with an agarose gel

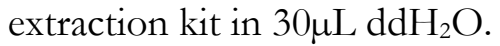

PCR 1:

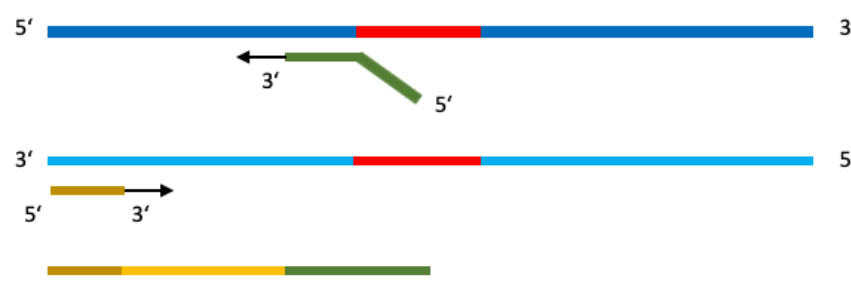

mRNA FLCN WT insert for pBabe puromycin plasmid

Primer Ol-2398

Complementary mRNA strand FLCN WT insert for pBabe puromycin plasmid

Primer OI-1468

PCR 2:

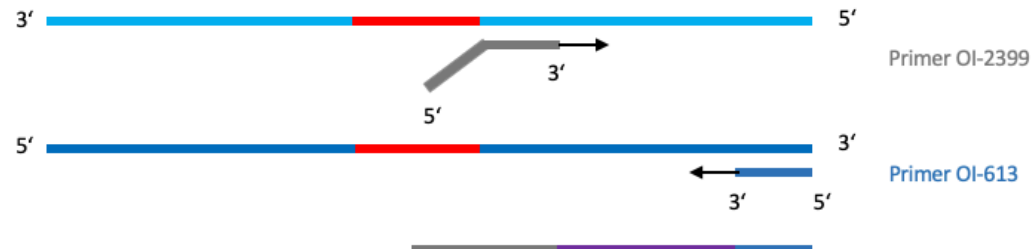

PCR 3: $\quad 5^{\prime}$

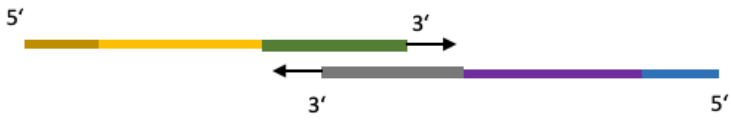

mRNA FLCN del insert for pBabe puromycin plasmid

Figure 5: Schematic of PCRs creating the patients FLCN mutation p.Gly84_Glu-132del as insert for a plasmid.

With the third and last PCR the whole insert for the plasmid is generated using the results of the first two PCRs as a template (Figure 5). These results now include the sequence before and after the deletion and are partly sense and antisense strands. Oligos OI-1468 and OI613 were used again for the beginning and end of the FLCN del pG84-E132 so it can be 
used as an insert for a $\mathrm{pBABE}$ puromycin plasmid. The result was controlled by running a sample of the PCR through a $0.8 \%$ agarose gel, it had the size of about 1650 base pairs.

The PCR was then purified using a QIAquick PCR purification kit (Fisher \#K310001) and eluted in $30 \mu \mathrm{L}$ of $\mathrm{ddH}_{2} \mathrm{O}$. Following digestion, the insert was ligated into the $\mathrm{pBABE}$ puromycin vector with BamHI and EcoRI restrictions sites. The results were confirmed through sequencing by the MGH DNA core facility.

Plasmids used for the Luciferase assay were already established in the lab as described by Zimmer et al. (2008).

\subsubsection{Retrovirus production and transduction of cells}

293T cells were transfected with retrovirus constructs and vector using lipofectamine as indicated by the products instructions (Invitrogen). $5 \mu \mathrm{g}$ of ampho-pac, VSV-G and plasmid DNA was mixed in $1 \mathrm{~mL}$ of DMEM as well as $37.5 \mu \mathrm{L}$ lipofectamine in a separate tube. After 5 minutes both tubes were mixed and set for 20 minutes. The mixture was added to the plates and after 6-12 hours the medium was changed.

Virus containing supernatant was harvested $24 \mathrm{~h}$ after transfection of $293 \mathrm{~T}$ cells, polybrene was added to the supernatant up to a concentration of $4 \mu \mathrm{g} / \mathrm{mL}$ and the supernatant was filtered through a $0.22 \mu \mathrm{M}$ filter. The filtrate was mixed in a 1:1 ratio with regular DMEM and added to 6-well plates of cells that were to be transduced. Plates were sealed and centrifuged at 4000RMP for 40 minutes at room temperature. After another 24 hours, selection medium was added, and protein expression was controlled by western blot or Luciferase assay.

\subsubsection{Cell cultures}

FTC133 is a FLCN-deficient human follicular thyroid carcinoma and was originally obtained from the American type culture collection (ATCC) (Laviolette 2017). HEK293T cells were also purchased from ATCC.

786-0 cells are derived from a clear cell renal adenocarcinoma were originally obtained from ATCC.

Cells were incubated at $37^{\circ} \mathrm{C}$ with $5 \% \mathrm{CO}_{2}$ and grown in Dulbecco's modified eagle medium (DMEM) with 10\% fetal bovine serum (FBS) and 1\% of Dulbecco's antibiotic mix of penicillin, streptomycin and glutamine if not stated otherwise. This mix is later referred to as regular DMEM.

\subsubsection{Incubation of cell cultures with HIF inhibitors}

All investigated compounds were synthesized by the laboratory of drug discovery in neurodegeneration. Upon arrival at the lab, compounds were dissolved in dimethyl sulfoxide 
(DMSO) to a concentration of $25 \mathrm{mM}$ in a clean tissue culture hood. Dissolved compounds were aliquoted and stored at $-80^{\circ} \mathrm{C}$.

For treatment of cells, compounds were added to the usual cell medium (regular DMEM or selection medium supplemented with $2 \mu \mathrm{g} / \mathrm{ml}$ puromycin for Luciferase assay) in 25 or $50 \mathrm{~mL}$ falcon tubes. For example, to treat $786-\mathrm{O}$ cells with a $10 \mu \mathrm{M}$ concentration of compound 83 , $4 \mu \mathrm{L}$ of the $25 \mathrm{mM} 83$ stock solution was added to $10 \mathrm{~mL}$ of regular DMEM at $37^{\circ} \mathrm{C}$. As control, $4 \mu \mathrm{L}$ of DMSO, also aliquoted and stored at $-80^{\circ} \mathrm{C}$, was added to another $10 \mathrm{~mL}$ of regular DMEM. Old medium of cell plates was aspirated, and the treatment medium was added carefully to the plates.

\subsubsection{Xenograft injections}

Animal experiments were carried out following the guidelines of the MGH institutional animal care and use committee according to an approved protocol. Cell lines were detached from cell plates using trypsin, washed and resuspended in phosphate buffered saline (PBS) and counted using a hemocytometer. Approximately 10 million cells resuspended in PBS with a total volume of around $300 \mu \mathrm{L}$ were injected subcutaneously into the right flanks of nude mice.

Four mice were injected for each cell line to be tested and tumor volume was regularly measured by a caliper and calculated using the equation length $(\mathrm{mm}) \mathrm{x}$ width $\left(\mathrm{mm}^{2}\right) / 2$. Tumors were harvested 47 days post injection.

\subsubsection{Luciferase assay}

This assay was conducted as described before (Zimmer et al. 2008). The 786-O cell line was used for this assay. To test the reduction of HIF $2 \alpha$ translation through the compounds, 786O cells were stably transduced with a plasmid coding for firefly luciferase under the control of 4 sequences of hypoxia responsive elements (later referred to as $7 \mathrm{H} 4$ cells). HIF2 $\alpha$ binds to specific DNA sequences termed hypoxia responsive elements (HRE) transactivating their target genes. Control cells were stably transduced with a Luciferase reporter constitutively active through the SV40 promoter, in a HIF-independent way (Later referred to as 7SV40 cells). Transduced cells were selected using regular DMEM supplemented with $2 \mu \mathrm{g} / \mathrm{ml}$ puromycin. The luciferase activity of $7 \mathrm{H} 4$ cells represents overall HIF2 $\alpha$ activity in the cells. Here, the luciferase reporter is only transactivated by HIF2 $\alpha$. If the cells are treated with compounds inhibiting HIF2 $\alpha$ translation, the overall HIF2 $\alpha$ protein levels are reduced and therefore the overall HIF $2 \alpha$ activity is suppressed; as a result, HIF $2 \alpha$ inhibitors specifically reduce Luciferase activity in $7 \mathrm{H} 4$ cells but not in the control 7 SV40 cells.

Cells were counted and plated on 24-well plates to a confluence of 50\% and incubated with the regular selection medium overnight. Cells were then treated with the compound to be tested, at various concentrations (usually 5 and $10 \mu \mathrm{M}$ ) for 6-8 hours and harvested with 90- 
100\% confluence. To detect the firefly luciferase activity, the Promega luciferase assay System (E1910) was used as described in the manual. Cells were grown on 24-well plates and three wells were treated with the same compounds each. Cells were washed on ice with cold PBS twice before $100 \mu \mathrm{L}$ of $1 \mathrm{x}$ passive lysis buffer was added. Plates were incubated on a rocker at $4^{\circ} \mathrm{C}$ for 30 minutes. $70 \mu \mathrm{L}$ of each sample were then transferred onto a 96 -well plate to allow faster pipetting with multi-channel pipets. To normalize the Luciferase signal to the total protein concentration of each lysate, protein concentration was measured by Bradford assay system (Bio-Rad \#5000006).

To measure the luciferase signal, $10 \mu \mathrm{L}$ of each sample was transferred onto a white 96-well plate and $10 \mu \mathrm{L}$ of luciferase assay reagent was added. The signal was then measured in a luminometer using the Softmax Pro software.

\subsubsection{Cell lysis}

Prior to cell lysis, plates were washed on ice with cold PBS five times. Cells were then scraped in $1 \mathrm{~mL}$ PBS into eppendorf tubes and spun down at around $2 \mathrm{~g}$ for 10 minutes at $4^{\circ} \mathrm{C}$. PBS was removed completely and the cell pellet was resuspended in $50 \mu \mathrm{L}$ of EBC lysis buffer (containing 50mM Tris(hydroxymethyl) aminomethane (Tris), $120 \mathrm{mM}$ sodium chloride $(\mathrm{NaCl})$ and 1\% Nonidet P-40 (NP-40)), supplemented with proteinase and phosphatase inhibitors. Cells were incubated on ice for 30 minutes. Samples were then centrifuged again at $4^{\circ} \mathrm{C}$ and $13,200 \mathrm{rpm}$ for 15 minutes to clear them of cellular debris and supernatant was transferred into a clean tube.

\subsubsection{Click chemistry}

The term click chemistry is used to describe chemical reactions that are biocompatible and join substrates with specific biomolecules (bioconjugation). This term evolved first in the process of synthesizing complex molecular structures by joining small units together (Kolb et al. 2001). Today click chemistry has many applications among them molecular synthesis, labeling or isolation of compounds. The most common type of click reaction is a Huisgen azide-alkyne cycloaddition between an azide and an alkyne group, forming a strong covalent bond (Figure 6). This method was used here to biotinylate compound 83, which includes an alkyne group in its structure, with biotin-azide. To perform the reaction the Click-It protein reaction buffer kit by Invitrogen was used according to the manufacturer's instructions (\#C10276). 


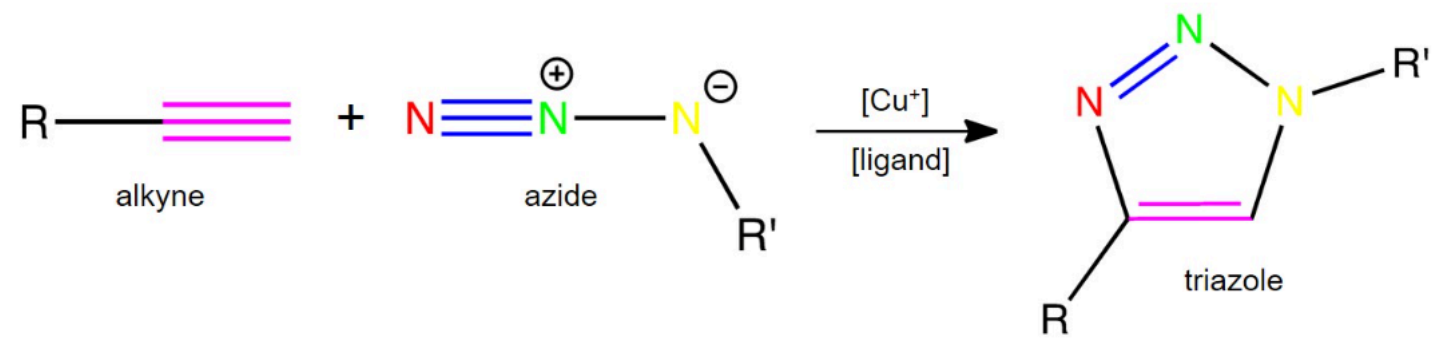

Figure 6: Copper-catalyzed azide-alkyne cycloaddition (Georgia Tech 2015)

Briefly, after cell lysis with EBC lysis buffer, $55 \mu \mathrm{L}$ of the cell lysates were mixed with all reaction reagents as indicated by the kit's instruction, including $100 \mu \mathrm{L}$ of reagent A supplemented with $40 \mu \mathrm{M}$ biotin-azide and incubated at room temperature for 20 minutes on a rotator. Afterwards proteins were precipitated using methanol and chloroform to wash off all reaction reagents. $600 \mu \mathrm{L}$ of methanol was added to each sample following $150 \mu \mathrm{L}$ of chloroform. After vortexing the samples shortly, $400 \mu \mathrm{L}$ of $\mathrm{ddH}_{2} \mathrm{O}$ was added and samples were centrifuged at $18,000 \mathrm{~g}$ for 5 minutes. The precipitated proteins then form a pellet between the lower hydrophobic phase and the upper aqueous phase. The upper phase is then carefully removed without disturbing the pellet which is then washed in $450 \mu \mathrm{L}$ of methanol twice. In between the washing steps the pellet is spun down again as stated before. After air drying the pellet with open lids for about 4 minutes it can be resuspended in $60 \mu \mathrm{L}$ of EBC lysis buffer, although concentrations of this buffer were optimized later (see results).

\subsubsection{Isolation via click reaction to azide coated beads}

For this procedure I used the Click-It protein enrichment kit form Invitrogen. 786-0 cells were treated with $10 \mu \mathrm{M}$ of each compound 83 or 76 for 16 hours. Cells were washed three times with PBS and lysed in EBC lysis buffer including protease and phosphatase inhibitors as stated above. For each sample, $30 \mu \mathrm{L}$ of azide magnetic beads were washed twice with PBS-T $(0.02 \%$ tween 20 in PBS), before $500 \mu \mathrm{L}$ of the lysates were added. To start the reaction, $500 \mu \mathrm{L}$ of $2 \mathrm{x}$ copper catalyst solution was added to each sample. The copper catalyst solution was prepared as stated by the kit's instructions. $1 \mathrm{~mL}$ of the $2 \mathrm{x}$ solution contains $835 \mathrm{~mL}$ of $\mathrm{ddH}_{2} \mathrm{O}, 125 \mu \mathrm{L}$ additive $1,20 \mu \mathrm{L}$ of $100 \mathrm{mM}$ copper(II)sulfate solution and $20 \mu \mathrm{L}$ of additive 2. Samples were rotated end-over-end for 16-20 hours at $4{ }^{\circ} \mathrm{C}$.

Following the click reaction each sample was washed 5 times with NT-N buffer containing $100 \mathrm{mM} \mathrm{NaCl}, 20 \mathrm{mM}$ tris and $0.5 \% \mathrm{NP}-40$. The beads were then resuspended in $500 \mu \mathrm{L}$ of this buffer and submitted for mass spectrometry analysis which was performed by a partner lab. 


\subsubsection{Immunoprecipitation and protein isolation via streptavidin}

For immunoprecipitation, cells were lysed with EBC lysis buffer as described above. $30 \mu \mathrm{L}$ per sample of magnetic protein A dynabeads were washed twice with PBS supplemented with $0.02 \%$ Tween 20 (PBS-T) and resuspended in $600 \mu \mathrm{L}$ of the washing solution. Anti FLCN antibody was added and tubes were rotated for two hours at $4^{\circ} \mathrm{C}$.

Coupled beads were again washed twice with PBS-T before the cell lysates were added and samples were again rotated at $4^{\circ} \mathrm{C}$ for 2.5 hours. Afterwards beads were washed 5 times with NET-N buffer (containing $100 \mathrm{mM} \mathrm{NaCl}, 20 \mathrm{mM}$ Tris, $1 \mathrm{mM}$ EDTA and $0.5 \% \mathrm{NP}-40$ ). To separate the proteins from the beads, they were boiled for 5 minutes at $95^{\circ} \mathrm{C}$ in SDS-PAGE sample buffer (containing $60 \mathrm{mM}$ tris, $2 \%$ SDS, 10\% glycerol and $0.003 \%$ bromophenol blue).

To isolate biotinylated compound 83 and bound proteins, samples were incubated with $50 \mu \mathrm{L}$ of magnetic streptavidin dynabeads for 30 minutes at room temperature. Beads were then washed five times with NT-NS buffer containing $500 \mathrm{mM} \mathrm{NaCl}$ and $1 \%$ SDS. Proteins were released from beads through boiling in $20 \mu \mathrm{L}$ of $1.5 \mathrm{x}$ sample buffer $(92.85 \mathrm{mM}$ tris, $3 \%$ SDS, $17.5 \%$ glycerol and $0.005 \%$ bromophenol blue) at $95^{\circ} \mathrm{C}$ for five minutes.

\subsubsection{Sodium dodecyl sulfate polyacrylamide gel electrophoresis (SDS-PAGE)}

SDS-PAGE allows the separation of proteins by their molecular mass in a polyacrylamide gel using an electric field. The method was first described by Laemmli (1970). The first step is the production of a polyacrylamide gel. This was poured in between two glass plates that were wiped clean with 70\% ethanol and separated by three plastic spacers, held together with paper clips. This gel cast was sealed using a 1\% agarose (Sigma Aldrich \#A2576) solution. The higher the polyacrylamide concentration in the gel, the smaller are the pores of the gel, through which the proteins wander. The polyacrylamide gel concentration should be adjusted to the molecular mass of the proteins to be separated. Here, I only used $8.75 \%$ polyacrylamide gels.

Table 5: Polyacrylamide gels

\begin{tabular}{lcc} 
& \multicolumn{2}{c}{ polyacrylamide gels } \\
Ingredients & Separating gel $(8.75 \%)$ & Stacking gel \\
\hline $\mathrm{ddH}{ }_{2} \mathrm{O}$ & $8.84 \mathrm{~mL}$ & $6.34 \mathrm{~mL}$ \\
$0.5 \mathrm{M}$ Tris, $0.4 \%$ SDS & - & $2.5 \mathrm{~mL}$ \\
$1.5 \mathrm{M}$ Tris, $0.4 \%$ SDS & $5 \mathrm{~mL}$ & - \\
$30 \%$ Acrylamide & $5.85 \mathrm{~mL}$ & $1.34 \mathrm{~mL}$ \\
$10 \%$ Ammonium persulfate & $200 \mu \mathrm{L}$ & $150 \mu \mathrm{L}$
\end{tabular}




\begin{tabular}{lcc} 
Ingredients & Separating gel (8.75\%) & Stacking gel \\
\hline $\begin{array}{l}\mathrm{N}, \mathrm{N}, \mathrm{N}, \text {, N'-tetramethyl- } \\
\text { ethylenediamine (TEMED) }\end{array}$ & $5 \mu \mathrm{L}$ & $20 \mu \mathrm{L}$
\end{tabular}

The lower, separating gel is poured into the glass cast first. $1 \mathrm{~mL}$ of pure butanol was poured on top of the gel carefully to get rid of any air bubbles and ensure a smooth interface. After polymerization (about 1 hour) the butanol was rinsed off with water and the stacking gel was poured on top before inserting a plastic comb, forming pockets for the samples inside the stacking gel. The stacking gel measured at least $2 \mathrm{~cm}$ from the bottom of the pockets. Once both gels are polymerized and proved for at least 1 hour, the plastic comb and the bottom spacer can be carefully removed, and the gel can be placed in an electrophoresis apparatus. The apparatus is then flooded with SDS running buffer (25mM Tris, $192 \mathrm{mM}$ Glycine and $0.1 \%$ SDS).

Prior to loading the gel, cell lysates were boiled for 5 minutes at $95^{\circ} \mathrm{C}$ in a $3 x$ SDS loading buffer containing $185.7 \mathrm{mM}$ tris, $6 \%$ SDS, 35\% glycerol and $0.01 \%$ bromophenol blue. SDS is a negatively loaded detergent that binds to proteins covering their own charges. To make sure that all samples run through the gel at the same speed the same volume of sample buffer and therefore the same amount of SDS has to be loaded into each well of the gel. By boiling the samples in this buffer, proteins are precipitated, and the rejection of their negative charges unfolds the proteins, allowing their separation in the gel by molecular mass. Longer proteins with a higher molecular mass run through the gel slower than shorter proteins. On both sides of the samples, a protein ladder (Precision Plus Protein Kaleidoscope) was loaded into the gel.

To separate the proteins, an electric field is generated in the gel $(60 \mathrm{~mA}$ while in stacking gel, $40 \mathrm{~mA}$ in separating gel, constant $250 \mathrm{mV}$ ). When in solution, particles in an electric field are drawn to the pole with the opposite charge. Through SDS, all proteins are negatively charged and therefore drawn to the positively charged pole of the electric field, the anode, that is generated in the lower part of the gel.

\subsubsection{Western blot}

Proteins separated in size through SDS-PAGE were then transferred again using an electric field onto a polyvinylidene fluoride (PVDF) membrane in a semi-dry transfer system. In this procedure, gel and membrane are put on top of each other between an electric field. Because of their negative charge, proteins again are drawn to the anode of the electric field and stick to the PVDF membrane, building hydrophobic and polar interactions.

The gel was carefully removed from the gel cast and the upper stacking gel and agarose sealing layer were removed. The gel was then transferred into the cathode buffer, containing $25 \mathrm{mM}$ tris, $142 \mathrm{mM}$ glycine and 10\% methanol. Inside the transfer machine, 3 layers of filter paper (Whatman) soaked in anode buffer I, containing 0.3M tris and 10\% methanol were 
placed. It is important to make sure that no air bubbles are trapped in between layers of filter paper since they interrupt the electric field. Meanwhile the membrane is "activated" in 100\% methanol for 1 minute. This process helps to remove the hydrophobic characteristics of the membrane and increases its interaction in the anode buffer II, containing $25 \mathrm{mM}$ tris and $10 \%$ methanol in which it is soaked before placing it on the filter paper stack. The gel is then placed directly on the membrane carefully, avoiding air bubbles again. On the gel, another three filter papers soaked in cathode buffer are placed and the "sandwich" is closed. Then an electric current is applied to the system using $15 \mathrm{~V}$ and $500 \mathrm{~mA}$ for 60 minutes. This forces proteins out of the gel that is on the cathode side of the field and onto the membrane towards the anode. Proteins stick to the membrane via hydrophobic and polar interactions.

After the transfer the membrane was incubated in blocking buffer containing $4 \%$ bovine serum albumin, $10 \mathrm{mM}$ tris, $150 \mathrm{mM} \mathrm{NaCl}$ and $0.5 \%$ Tween 20 , for 60 minutes. This process blocks all the open spots of the membrane, avoiding unspecific protein binding.

In order to detect one specific protein on the membrane, it is incubated with blocking buffer supplemented with an antibody targeting the protein of interest overnight at $4^{\circ} \mathrm{C}$. The membrane was cut with a razor blade to incubate different parts of the membrane with different antibodies. The standard protein ladder visible from SDS-PAGE was used for orientation to cut the membrane.

To visualize the primary antibody, it is stained with a secondary antibody (anti-rabbit or antimouse) bound to horseradish peroxide (HRP). Before incubation with the secondary antibody, the membrane is washed three times for 15 minutes with TBS-T $(10 \mathrm{mM}$ tris, $150 \mathrm{mM} \mathrm{NaCl}$ and $0.5 \%$ Tween 20 ) at room temperature. Secondary antibody was then applied in TBS-T as well for 60 minutes in a dilution of 1:10,000. The membrane is then washed again three times as described before. The targets are visualized through short incubation with a developing solution (Western Lightning Plus-ECL, Perkin Elmer) and detected with a Bio-Rad ChemiDoc system.

To stain the PVDF membrane for biotinylated compound 83, it was incubated with streptavidin-HRP right after the transfer for 1 hour at room temperature with light agitation. Instead of using blocking buffer, TBS-T was supplemented with 5\% milk powder and streptavidin-HRP was added in a dilution of 1:2,000. The membrane was then washed three times in TBS-T and developed as described above.

To detect proteins by ponceau $\mathrm{S}$ the membrane was incubated with ponceau $\mathrm{S}$ solution containing $0.1 \%$ ponceau $\mathrm{S}$ and $5 \%$ acetic acid in $\mathrm{ddH}_{2} \mathrm{O}$ for 1 hour at $4^{\circ} \mathrm{C}$ with light agitation. It was then washed in $\mathrm{ddH}_{2} \mathrm{O}$ until clear bands were visible.

\subsubsection{Silver nitrate staining of polyacrylamide gels}

Proteins in the polyacrylamide gel after electrophoresis were fixed overnight in a ddH2O based solution containing 20\% methanol and 10\% acetic acid. Gels were then washed for 
30 minutes in a $50 \%$ ethanol solution followed by a second wash with only ddH2O for 15 minutes. They were then incubated for 15 minutes in $300 \mathrm{~mL}$ ddH2O containing $25 \mu \mathrm{L}$ of a $1 \mathrm{M}$ dithiothreitol (DTT) stock solution followed by one hour of incubation in a $0.2 \%$ silver nitrate solution. Gels were developed in a 3\% sodium carbonate and $0.02 \%$ formaldehyde solution up to the desired contrast for about 10-15 minutes. The reaction was stopped by washing the gel in $1 \%$ acetic acid solution.

Desired gel sections were cut out using a clean razor blade and stored in Eppendorf tubes. To destain gel sections two destaining solutions were prepared. Solution 1 was $60 \mathrm{mM}$ potassium ferricyanide (Sigma Aldrich \#244023) and solution 2 200mM of sodium thiosulfate (Sigma Aldrich \#72049) in $\mathrm{ddH}_{2} \mathrm{O}$. These solutions were mixed 1:1 and $400 \mu \mathrm{L}$ of the mixture was added to each gel section and incubated for 5 minutes at room temperature. Gel sections were then washed with $\mathrm{ddH}_{2} \mathrm{O}$ until they were clear about 5 times for 5 minutes and submitted to the Taplin mass spectrometry facility of Harvard Medical School for mass spectrometry analysis.

\subsubsection{Mass spectrometry analysis}

Mass spectrometry analysis was performed by members of the Haas laboratory of the Massachusetts General Hospital Center for Cancer Research. The procedure was described previously by Lyons et al. in 2018. Disulfide bonds were reduced using DTT and cysteine residues alkylated with iodoacetamide. A two-step process was then used to digest proteins. The first step was digestion with $3 \mu \mathrm{g}$ of endoproteinase $\mathrm{Lys} C$ at room temperature overnight following 6 hours of $3 \mu \mathrm{g}$ of sequencing-grade trypsin at $37^{\circ} \mathrm{C}$. The reaction was stopped with trifluoroacetic acid. The digest was then separated from the azide magnetic beads. To desalt the samples, they were run through solid-phase extraction cartridges (Sep-Pak C18). Peptides were then vacuum dried and stored at $-80^{\circ} \mathrm{C}$.

Mass spectrometry analysis of silver stained SDS-PAGE gel was performed by the Taplin Mass Spectrometry Facility of Harvard Medical School. Reduction, alkylation and digestion of the proteins were performed before extracting the peptides from the gel.

For labeling with tandem mass tag reagents, peptides were resuspended in 200mM 4-(2hydroxyethyl)-1-piperazineethanesulfonic acid (HEPES) ( $\mathrm{pH} 8.5$ ), 30\% acetonitrile, and 5 $\mu \mathrm{L}$ of tandem mass tag reagent, suspended in 30\% dry acetonitrile as well. Samples were incubated for 1 hour at room temperature and the reaction was stopped by adding $6 \mu \mathrm{L}$ of $5 \%$ hydrolxylamine in $200 \mathrm{mM}$ HEPES solution. Solutions were again acidified with $50 \mu \mathrm{L}$ of $1 \%$ trifluoroacetic acid and desalted as described earlier.

Samples were then fractionated by basic $\mathrm{pH}$ reversed-phase liquid chromatography sample fractionation. Resuspended samples were separated using a $4.6 \mathrm{mmx} 250 \mathrm{~mm}$ Zorbax ExtendC18 column on an Agilent 1260 high-performance liquid chromatography system. 
For mass spectrometry data acquisition, tandem mass tagged peptides were subjected to multiplexed quantitative proteomics analysis on an Orbitrap Fusion mass spectrometer. After separation over different micropapillary columns, samples were eluted, and peptides were identified using MS2 spectra and quantified with MultiNotch MS3 method in a datadependent mode (McAlistor et al. 2014). The acquired data was analyzed through an in-house SEQUEST-based software platform (Eng et al. 1994). 


\section{$3 \quad$ Results}

\subsection{A novel FLCN mutation promoting tumor growth in vivo}

\subsection{1 "Early onset renal cell carcinoma in an adolescent girl with germline $F L C N$ exon 5 deletion" (Schneider et al. 2018)}

The results presented here have been published as a case report titled "Early onset renal cell carcinoma in an adolescent girl with germline FLCN exon 5 deletion" by Meike Schneider, Katja Dinkelborg et al. in the Familial Cancer journal (Schneider et al. 2018). We report on a 14-year-old girl with RCC of the left kidney who was referred to the Massachusetts General Hospital genitourinary cancer genetics clinic. Except for a palpable abdominal mass, physical examination of the patient and the medical history were unremarkable.

The patient underwent nephrectomy of the left kidney. Histological as well as immunohistochemical examination of the tumor failed to classify the tumor as one of the known histologic entities. Genetic testing however revealed an in-frame deletion of exon 5 in the FLCN gene (p.Gly84_Glu-132del in exon 5) (Figure 7a). The patient's father carries the same FLCN mutation, but he has no renal cysts or masses by abdominal magnetic resonance imaging (MRI). Neither the index patient nor her father or any of the father's relatives had a history of RCC. Furthermore, there was no history of any skin fibrofolliculomas or spontaneous pneumothorax.

\subsubsection{FLCN germline intragenic deletion encodes a stable protein when reintroduced in $F L C N$-null cells}

Given the lack of family history or other phenotypical BHD characteristics, as well as the early onset of RCC in this patient, it was important to show that the genetic mutation leading to the altered FLCN protein was responsible for the proband's tumor. To test this, we cloned the mutant FLCN into a tumor cell line, proved expression of stable protein and tested whether the insertion lead to a tumorigenic phenotype. To this end a new plasmid encoding a FLAG-tagged FLCN protein harboring the patient's FLCN mutation was designed (see 2.2.1 for detailed information). A pBabe-puromycin plasmid expressing WT FLCN protein was used as template (already present in the lab, Laviolette et al. 2017).

FLCN-null FTC133 cells were stably transcribed with WT FLCN, FLCN harboring the patient's deletion (FLCNdel5) or empty vector as control. Western blot of stably infected cell lines showed a stable protein encoded by the FLCNdel5 mutant (Figure 7b). The lower molecular weight is consistent with the 48 amino acid deletion and the finding that the band on the gel has the same intensity as the wildtype FLCN transfected protein indicates that the mutant protein is transcribed at an equivalent level and stable. 


\subsubsection{In vivo assay shows loss of tumor growth suppression by FLCN mutant}

To assay for the effect of this mutant on the function of FLCN, FLCN-null FTC133 cells infected with WT FLCN, the patient's FLCN mutant or empty vector as control were injected in the flank of nude mice. Cells expressing FLCN WT did not form a tumor (Figure 7c, d). In contrast to WT expressing cells, cells that expressed the FLCNdel5 or infected with empty vector generated tumors in mice. Taken together these results show that the in-frame mutation is encoding a stable protein that has lost its ability to suppress tumor growth. The in vivo tumor suppression assay was used, in our case, to evaluate the functional outcome of a clinically identified mutation, the nature of which could not be a priori predicted by its molecular changes. Thus, the tumor xenograft assay is a validated approach to test the functional effect of novel FLCN mutations.

A

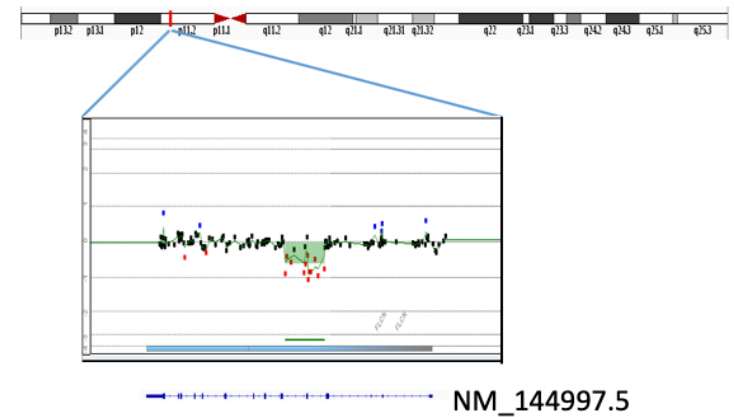

C

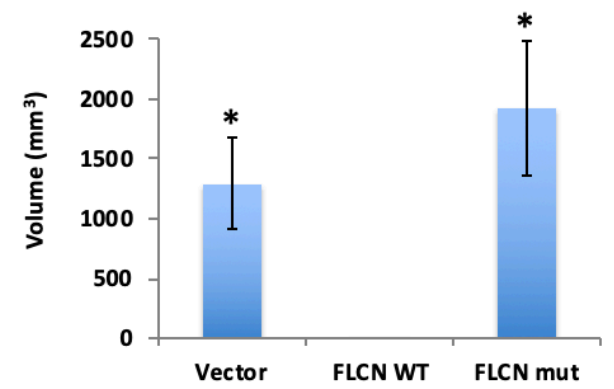

B

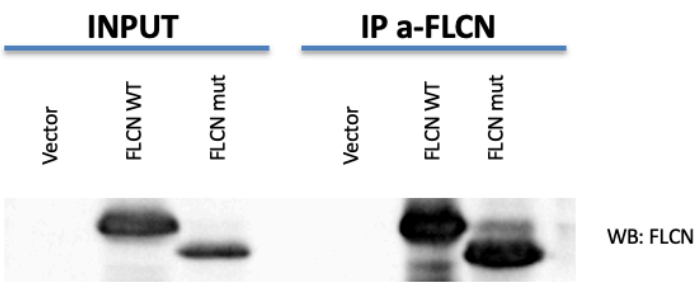

D

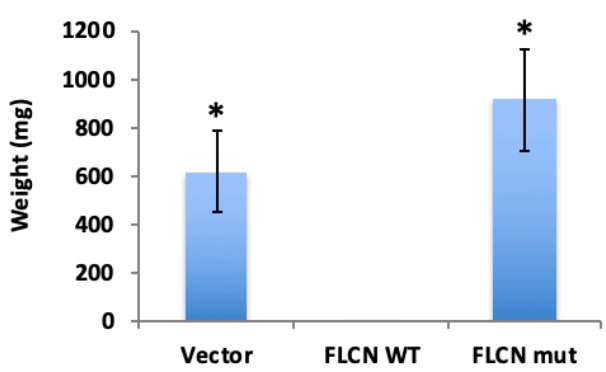

Figure 7: "Patient's germline in-frame mutation inactivates FLCN tumor suppressor gene." (Schneider et al. 2018)

A "Exon level CGH microarray reveals deletion in FLCN gene. B FLCN p.Gly84_Glu132del encodes a stable protein when reintroduced in FLCN-null cells. FLCN protein was immunoprecipitated by anti-FLCN antibody from cells stably infected with vector only, wild type FLCN gene or the FCLN p.Gly84_Glu132del mutant, as indicated. Immunoprecipitated proteins were detected by immunoblot with the same anti-FLCN antibody. C-D Reintroduction of FLCN wild type but not the FLCN p.Gly84_Glu132del mutant in FTC133 FLCN-null cells suppresses their growth as tumor xenografts in immunocompromised mice. Asterisk indicates comparison to FLN WT corresponding value, $\mathrm{p}<0.02$, Student's t test." (Schneider et al. 2018, with kind permission of Familial Cancer)

Unpublished data from the Iliopoulos laboratory, currently under review, showed the interaction of FLCN with two translation initiation factors. FLCN downregulated protein 
translation in an mTOR independent manner. The c-terminal region of FLCN is crucial for this interaction. Interestingly, in this patients' mutation the c-terminal region remains intact. Nonetheless the mutant is tumorigenic implicating an important function of region Gly184Glu132. This suggests that the region of FLCN encoded by exon five is crucial for its function.

\subsection{Identification of proteins involved in HIF regulation}

\subsubsection{Compound 83 can be modified by click-chemistry and is active}

The goal of this effort is to identify cellular proteins interacting directly with the HIF2 $\alpha$ small molecule inhibitors. As compound 76 was used in different studies in the lab confirming its function, its structure was used as orientation for further experiments to identify target proteins. Compound 76 consists of a thiophene core with two different functional arms bound to it. One arm consists of a ester group and the other is bound via hydrazine group and has a sulfur dioxide group at the end (Figure 8a). Compound 76 has a molecular mass of $287 \mathrm{~g} / \mathrm{mol}$.

To be able to isolate the compound from a cell lysate we substituted the methyl group of the ester arm with an azide group and called this compound 83 (Figure 8a). The method that was used to synthesize this compound was published by Wang et al. (2019). Compound 83 has a slightly higher molecular weight of $311 \mathrm{~g} / \mathrm{mol}$. Luciferase assays confirmed its unaltered activity compared to 76 (Figure 8a).

\subsubsection{Visualization of protein bands bound by compound 83}

Lysates of cells treated with compound 83 or DMSO control were processed in a click reaction to link biotin to the small molecule inhibitor. Biotin was covalently bound via an alkyne group to the azide group of compound 83 but not to compound 76 which does not contain the azide group. Following the click reaction, cellular proteins were precipitated (as described in the methods), resuspended and separated by SDS-PAGE. Electrophoresed proteins were transferred to a PVDF membrane and western blotted with streptavidin HRP. Results showed a specific reproducible pattern of protein bands, detected by streptavidin (Figure 8b).

To separate the proteins by size in an SDS-PAGE, the procedure includes boiling the samples in 3\% SDS buffer. This step of the procedure precipitates the proteins and usually breaks down non-covalent interactions within their molecular structure or between different proteins. If compound 83 binds its target proteins in a non-covalent way, this interaction would be broken as well. In this case, the compound alone would run through the SDSPAGE and the streptavidin staining would not identify protein bands. These data therefore 
strongly suggest that compound 83 binds covalently to a specific set of target proteins. However, it is not clear how compound 83 and its analogs bind the proteins.

To control for non-specific binding of compound 83 to cellular proteins, cells were treated with compound 671 . This latter compound is similar to 83 and bears an azide group that can "click" with the alkyne group of biotin. In contrast to compound 83, compound 761 was modified so that it does not inhibit HIF2 $\alpha$ activity in a luciferase assay. It is including the azide group, but without showing any activity in the luciferase assay (Compound 671). The hypothesis is that since compound 761 does not inhibit HIF2 $\alpha$ function it does not form covalent bonds with the protein targets critical for suppression of HIF2 $\alpha$ translation. Indeed compound 671 appeared not to interact covalently with endogenous proteins (Figure 8b).

In addition, to control for non-specific binding of biotin to cellular proteins, we used compound 76 treated cells for a click reaction. Compound 76 does not display an azide group and therefore any protein detected by biotin streptavidin interaction can be attributed to non-specific binding of biotin directly to the protein but not to the interaction of the chemical inhibitor to the target protein. Similarly, to compound 761, treatment with compound 76 did not lead to the detection of target proteins (Figure 8b). The experiments using compound 76 and 761 confirmed the specificity of the procedure. They indicate that compound 83 interacts specifically with a set of proteins likely involved in suppression of HIF2 $\alpha$ translation and that the assay we used to identify proteins is specific to the interaction of compound 83 to its target.

To further validate the specificity of this assay, we tested the hypothesis that if compound 76 and 83 bind to the same proteins they may "compete" with each other for binding. We treated cells with a combination of compound 76 (active but not clickable) and compound 83 (active and clickable). Both, compounds 76 and 83, should bind the same proteins but only those bound to 83 are biotinylated via click reaction and stained with streptavidin on the membrane. Indeed, we showed that "cold" compound 76 competes with compound 83 for protein binding. The biotinylation of protein targets through binding of compound 83 for was reduced by treatment with compound 76 (Figure 8c). 


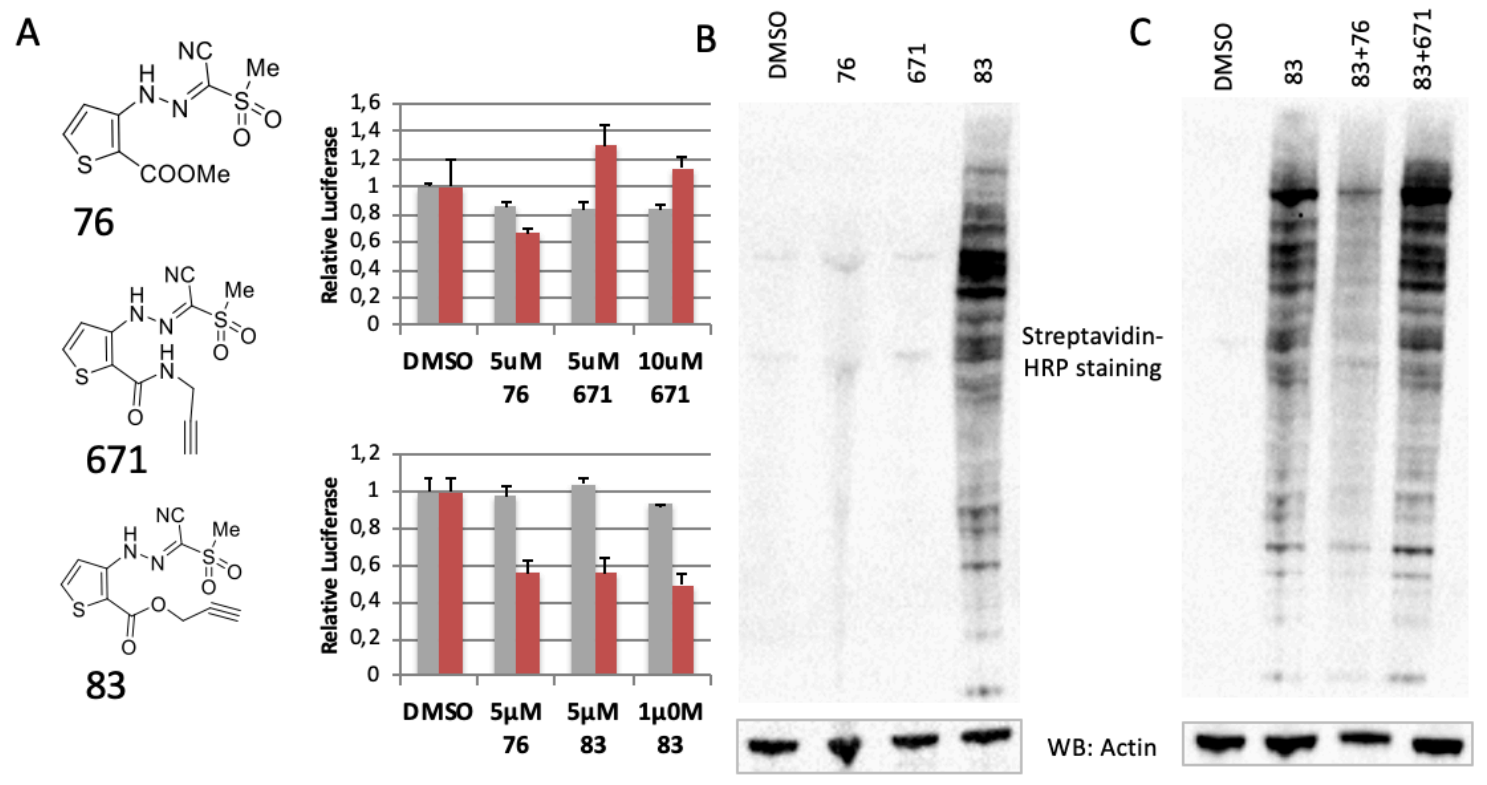

Figure 8: Compounds' structure, activity, and bound proteins.

A Activity of the compounds is shown through luciferase assay. The graphs in grey represent the relative luciferase signal from control cells, stably infected with a constitutively expressed firefly luciferase reporter. Red graphs represent the luciferase expression regulated through hypoxia responsive elements (HRE), only active when bound by HIF. A reduced luciferase signal represents a lower concentration of HIF in the cells. Compound 83 is as active as lead compound 76 whereas compound 671 does not show activity in downregulating HIF translation. B Western Blot of lysates of cells treated with different compounds $(5 \mu \mathrm{M})$ each for 8-10 hours. A click reaction with biotinazide was performed and through the biotinylation of compound 83 protein bands of its covalently bound proteins are stained with streptavidin HRP. C Same protocol as described in b with the difference of simultaneous treatment to see if other active compounds compete with compound 83 in binding the target proteins, therefore reducing signal in simultaneously treated cells compared to cells only treated with compound 83 .

\subsubsection{Isolation of cellular proteins interacting with HIF2 $\alpha$ inhibitors}

Identification of the proteins bound to the lead compounds, requires their isolation from all other proteins in the cell lysates. For this isolation we used streptavidin coated beads. Cells were incubated with compound 83 overnight. After cell lysis and performing the click reaction that biotinylates compound 83 , samples were incubated with streptavidin beads. The beads were then washed, and the biotin-streptavidin interaction was broken by boiling the samples. Eluted proteins were resolved in SDS-PAGE, transferred to a PVDF membrane and detected by streptavidin HRP.

This experiment showed the pattern of eluted proteins of the whole lysate as described previously in paragraph 3.2.2 (Figure 9a). The isolation procedure did not alter appreciably the composition of the biotinylated proteins.

The streptavidin HRP staining can only detect proteins covalently interacting with biotinylated compounds. To check for unspecific binding to beads (background), the same 
membrane was stained with a Ponceau S solution. In contrast to staining with streptavidin, Ponceau S stains all proteins, independently of their interaction with HIF2 $\alpha$ inhibitors. Ponceau $S$ staining revealed that there is a significant degree of non-specific binding of proteins to the beads (Figure $9 \mathrm{~b}$ ). However, this again confirmed the specificity of detecting proteins that interact with HIF2 $\alpha$ inhibitors by streptavidin staining after treating cells with the biotin loaded compounds.

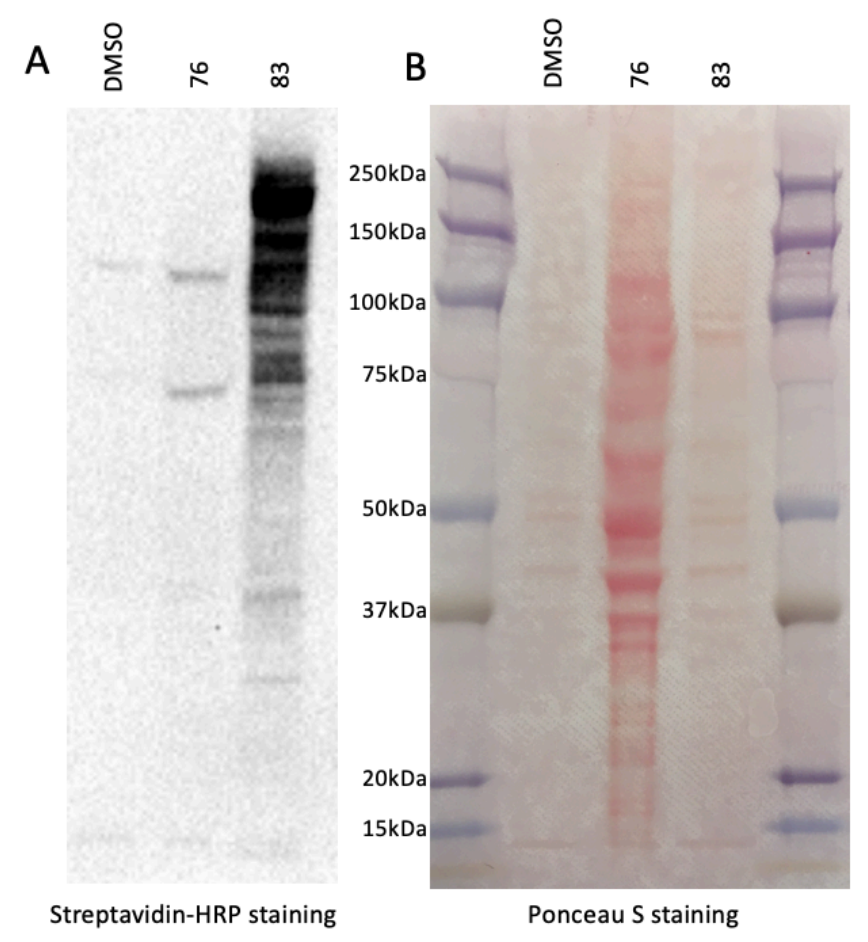

Figure 9: Isolation of the compounds and bound proteins by a streptavidin pull-down assay.

A 786-0 cells were treated with compound 76, 83 or vector only control (DMSO). After 12h of treatment, cells were lysed and compound 83 was biotinylated via click reaction. streptavidin coated beads were added to samples and rotated for $30 \mathrm{~min}$. Beads were washed, and proteins boiled of in SDS buffer for SDS-PAGE. Western blot was stained with streptavidin-HRP. streptavidin pull-down shows a similar protein band pattern as only biotinylation (Figure 8b). B Ponceau S staining of the same membrane shows high background in control cells treated with compound 76.

\subsubsection{Resolving of a high protein background}

In an effort to reduce the non-specific protein background, we tried optimization of different steps of the protocol. The first problematic step seemed to be the complete suspension of the protein pellet after the click reaction. To separate the product of the click reaction from the reagents, proteins are precipitated with methanol and chloroform. For the isolation, it is crucial that the pellets are suspended completely in a sodium dodecyl sulfate (SDS) containing buffer.

At first, we used EBC lysis buffer for suspension of the pellet. This buffer contains $1 \%$ SDS. The samples were heated to $70^{\circ} \mathrm{C}$ for 10 minutes. To get rid of flakes remaining from the protein pellet, we increased both the SDS concentration of the buffer and the heating 
temperature. In addition, samples were centrifuged though glass wool at 18,000g for 5 minutes. The best results were gained with SDS concentration of $2 \%$ and boiling at $95^{\circ} \mathrm{C}$ for 5 minutes (Figure 10a).

In another approach to resolve unspecific protein background, different wash buffers were tested. Here we varied both the $\mathrm{NaCl}$ and SDS concentrations in a NT-N buffer containing $\mathrm{NaCl}, 20 \mathrm{mM}$ Tris and NP-40. When we washed the beads that "pulled down" the proteins with buffer containing $500 \mathrm{mM} \mathrm{NaCl}$ and $1 \%$ SDS we were able to significantly reduce the non-specific binding of proteins to beads (Figure 10b).

\begin{tabular}{|c|c|c|c|c|c|c|}
\hline treatment & \multicolumn{4}{|c|}{ Compound 83} & \multirow{3}{*}{$x$} & \multirow{3}{*}{$\begin{array}{l}\infty \\
\infty \\
5 \\
\underline{2}\end{array}$} \\
\hline temperature & \multicolumn{2}{|l|}{$75^{\circ} \mathrm{C}$} & \multicolumn{2}{|c|}{$95^{\circ} \mathrm{C}$} & & \\
\hline SDS concentration (\%) & 1 & 2 & 2.5 & 3 & & \\
\hline
\end{tabular}

\begin{tabular}{|c|c|c|c|c|c|c|c|c|}
\hline treatment & vec & & Compo & nd 83 & & & \multirow{3}{*}{$x$} & \multirow{3}{*}{$\begin{array}{l}\stackrel{\infty}{\infty} \\
\underline{a} \\
\underline{a}\end{array}$} \\
\hline $\begin{array}{l}\mathrm{NaCl} \text { concentration } \\
(\mathrm{mM})\end{array}$ & 125 & 250 & 500 & 125 & 250 & 500 & & \\
\hline SDS concentration (\%) & \multicolumn{3}{|c|}{0} & \multicolumn{3}{|c|}{1} & & \\
\hline
\end{tabular}

A

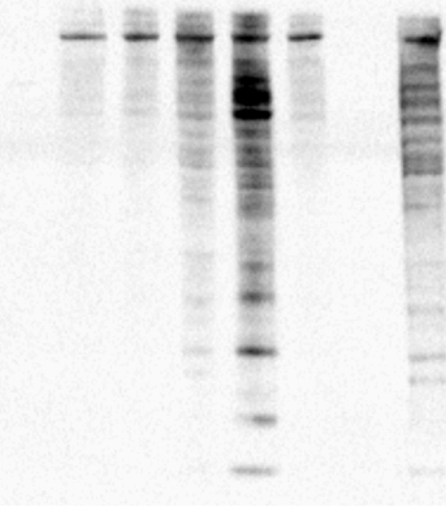

B

Figure 10: Optimization of streptavidin pull-down.

A Streptavidin pull-down of 786-0 cells treated with compound 83 or DMSO (vec) overnight. Different conditions were used for the resuspension of the precipitated protein pellet after click reaction. After washing with methanol, pellets were suspended in $50 \mathrm{mM}$ Tris buffer with different SDS concentrations as stated in the table. Samples were then heated for $5 \mathrm{~min}$ to different temperatures to facilitate suspension. B After isolation of biotinylated compound 83 and bound proteins with streptavidin coated beads, different wash buffers were used to clean beads of unspecific bound proteins. All wash buffers contained $20 \mathrm{mM}$ Tris- $\mathrm{HCl}, 0.5 \%$ Nonidet P- $40 . \mathrm{NaCl}$ concentrations were increased in buffers with or without adding SDS. Even with $500 \mathrm{mM} \mathrm{NaCl}$ and $1 \%$ SDS clear results can be obtained.

\subsubsection{Identification of candidate target proteins}

Different approaches were taken to identify the proteins in the bands visible when detected by streptavidin-HRP: Multidimensional protein identification technology (MudPIT) and SDS-PAGE protein separation followed by selected protein elution and spectrometry.

As a first approach the candidate target proteins were pulled-down via a direct click reaction to azide magnetic beads (Click Chemistry Tools \#1036-1). Lysates of cells treated with compound 83 or compound 76 were used. After the click reaction the beads were washed in a wash buffer containing $100 \mathrm{mM} \mathrm{NaCl}, 20 \mathrm{mM}$ Tris and $0.5 \%$ NP-40. The beads were 
submitted to a partner lab for on resin digestion followed by mass spectrometry analysis. To ensure reproducibility, four "positive" samples of cells treated with compound 83 and four "negative" samples of cells treated with compound 76 were analyzed. Spectrometry analysis produced a list of proteins isolated from cells treated with compound 83 or 76 .

From this analysis we compared the averages of the number of peptides identified from all samples treated with 76 with the averages of the four samples treated with compound 83 . We then considered only the proteins identified at least twice as often as in the samples treated with 83 . This gave us a list of 58 proteins.

Specific criteria were applied to narrow down the list of proteins that are candidate targets of the compound: 1) Only the proteins identified by at least two different peptides were considered, 2) The proteins that were abundant so that they produce at least a total of 10 peptideswere considered, 3) From the subset that conformed to all the criteria listed in 1 and 2 , the proteins with the predicted molecular weights corresponding to pull-down bands resolved by SDS-PAGE and detected by streptavidin HRP staining were considered (Figure 11a). Based on criteria 1-3, the following proteins constitute a "short list" of direct targets of HIF2 $\alpha$ inhibitors: a) peflin 1, a 30kDa calcium binding protein, b) YRDC, a mitochondrial protein $(29 \mathrm{kDa})$, and c) FAM133B (28kDa), which may be involved in RNA binding. Unfortunately, using this approach, we could not identify any proteins that could represent the strong band visible in the pull-downs at around $100 \mathrm{kDa}$. Because this experiment was done with azide coated beads, we could not optimize the purification of these samples to the same extend as described earlier with streptavidin coated beads. In this experiment the beads were washed less stringent than the streptavidin coated beads.

As a second approach, proteins isolated by pull-down of lysates treated with 83 or DMSO with streptavidin coated beads were resolved by SDS-PAGE. Proteins in the gel were then stained with silver nitrate (Figure 11a). Protein bands detected by silver nitrate in the lysates of cells treated with 83 but absent in the lysates of cells treated with DMSO were considered specific. We cut these bands out of the gel and submitted the gel content to in gel digest and mass spectrometry to the Taplin mass spectrometry facility of Harvard Medical School in order to identify the protein(s) represented by the band. As controls we used the corresponding gel area in the lane resolving the proteins pulled down from cells treated with DMSO. In total, we submitted 5 samples from each lane. The samples were cut out from around $170 \mathrm{kDa}, 100-150 \mathrm{kDa}, 100 \mathrm{kDa}, 45 \mathrm{kDa}$, and $30 \mathrm{kDa}$ (Figure $11 \mathrm{~b}$ ). In this approach fewer proteins were identified in each sample since only a part of the whole lysate was analyzed. To again narrow down the list of proteins similar criteria as mentioned above were applied. 1) Only the proteins with the molecular weight corresponding to the gel area that the sample had been cut out from were considered specific. 2) Only the proteins that were identified in the 83 lane but not in the corresponding section of the DMSO lane were considered. The following proteins were identified through this approach: a) iron regulatory protein 1 (IRP1, 98kDa), b) tumor susceptibility gene 101 (TSG101, 44kDa), and c) 
phosphoglycerate kinase 1 (PGK1, 45kDa). When secreted by tumor cells, PGK1 acts as a disulphide reductase, enabling tumor angiogenesis (Lay et al. 2000). Interestingly, peflin was also identified by mass spectrometry analysis of section 5 (Figure 11b).

Taken together, the second isolation procedure was much more optimized prior to mass spectrometry analysis and might be a cleaner approach. Interestingly, it confirmed interaction of the compounds to IRP1, which was also suggested as a possible target protein in earlier studies (Zimmer et al. 2008), following a completely different approach, thus validating the pull-down. Also, peflin was identified as a candidate target by both procedures. However, apart from peflin, the analysis led to different results and should be validated by repetition or further investigation in the identified proteins.

A

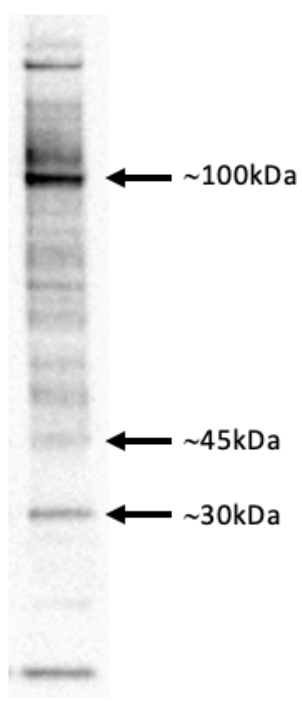

B

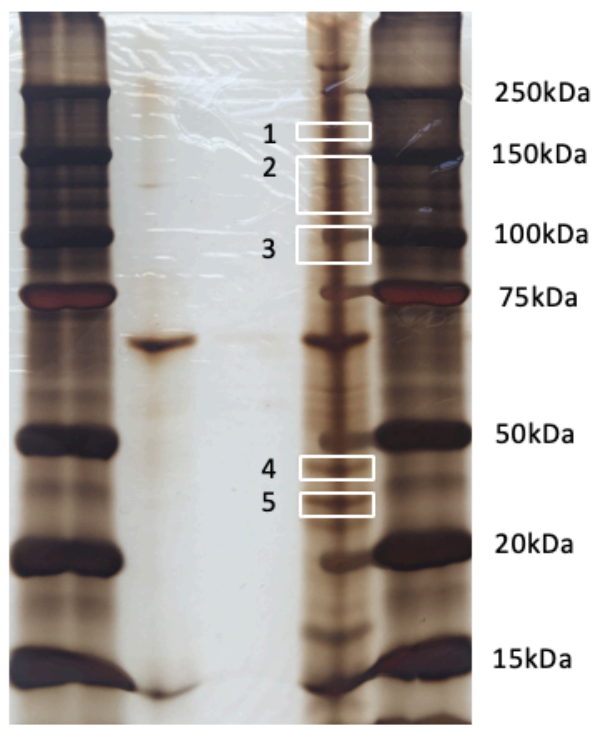

C DMSO 83
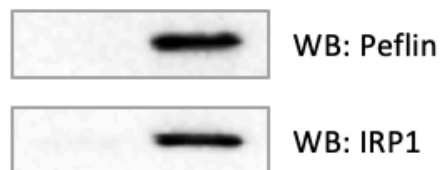

Figure 11: Identification of candidate target proteins.

A Protein lane taken from figure 10b with bands and their approximate molecular weight indicating identified proteins by mass spectrometry analysis. B Silver-nitrate stained polyacrylamide gel after electrophoresis showing lysates of cells treated with DMSO or compound 83. After a click reaction with biotin-azide proteins where isolated using streptavidin coated beads. C Western blot of corresponding lysates from A. Western blot incubated with either anti-peflin or anti-IRP1 antibodies show positive results for cells treated with compound 83 but not DMSO.

To validate the proteins identified by mass spectrometry analysis we western blotted cell lysates as described above for the suggested target proteins. For this experiment the same pull-down protocol as described above (3.2.3) was used. Cells were treated with compound 83 or DMSO, after cell lysis a click reaction with biotin-azide was performed, compound 83 and its bound proteins were isolated with streptavidin coated beads. After SDS-PAGE and transfer to a PVDF membrane, instead of staining the membrane with streptavidin HRP as before it was now incubated with antibodies against the identified candidate target proteins, YRDC, FAM133B, peflin and IRP1. Both peflin and IRP1 showed positive results suggesting the binding of the compounds to these proteins (Figure 11c). TSG101 and PGK1 have not been tested using this assay. 


\section{Discussion}

\subsection{Can we predict whether a novel FLCN mutation leads to loss-of- function and therefore to be tumorigenic in BHD syndrome?}

In hereditary diseases such as BHD syndrome it is not always given to predict how a specific mutation effects the proteins' function. Here, we show through an in vivo assay, using mouse xenografts, that a novel FLCN mutation lead to a tumorigenic phenotype. In this case, it was specifically interesting because of the unusual family and patient history, but also because the mutation did not affect the $\mathrm{c}$ terminal region of the protein, as most mutations in BHD syndrome do (Lim et al. 2010).

The availability of a functional assay may expedite the clinical diagnosis by helping to functionally classify the mutation. In the long term this assay could be used to further look into a genotype-phenotype correlation in patients with BHD syndrome. Comparison of growth rate and histopathological features of grown xenografts with different FLCN mutations might lead to new insights into FLCN function and pathway regulation.

Recommendations for patient surveillance suggest abdominal imaging for kidney tumor detection starting at the age of 20 (Jensen et al. 2017). Jensen et al. also recommend that abdominal scans are repeated every two years if a tumor is detected. Close surveillance is especially important to detect the aggressive, fast growing RCC types among BHD patients. Patient surveillance and management could be more specific if the BHD phenotype could be predicted by the FLCN mutation detected in the patient. In addition, the publication of this case raises awareness of the possibility that the age of onset of RCC in a BHD patient may be as early as in adolescent years. This would strongly suggest that baseline screens for RCC in BHD patients is necessary as early as in adolescence.

In addition, we report on a highly interesting case of BHD disease. We provide proof that a newly identified FLCN mutation, not affecting the c-terminal region of the protein, is a driving cause of RCC in a BHD patient. Since most of the detected FLCN interactions are linked to its c-terminal domain, this finding can provide new insight into FLCN structure or function. Especially since detection of the mutant protein by western blot analysis suggest a somewhat stable protein and the tumorigenic effect is not due to the loss of FLCN in total.

These observations are especially interesting considering the recent structural identification of the FLCN/FNIP2 complex by Lawrence et al. and Shen et al. (2019). Both groups investigated the role this complex plays in serving as a GTPase activating domain to Rag C, leading to the activation of mTORC1 dependent on amino acid availability in the cell. Shen et al. found out that FLCN and FNIP2 heterodimerize via Longin domains that are localizing at the space between both nucleotide binding sites of RagA and RagC. The Longin domains are localized at the n-terminal regions of both proteins, placing the patients' deletion from amino acid 84 to 132 within this region. 
Even more we could identify the deleted region of the patients' FLCN mutant to represent the $\alpha \mathrm{L} 1$ helix of FLCN, directly interacting with the nucleotide binding site of RagA (Figure 12). This suggests that the patients' FLCN mutant protein loses its function to activate GTP hydrolysis of Rag C enabling mTORC1 activation. In some way this hypothesis contradicts the assumption that FLCN, as a tumor suppressor protein, enables the activation of oncogenic pathways such as mTORC1. Upregulation of mTORC1 has been shown in BHD associated tumors (Hasumi et al. 2009).

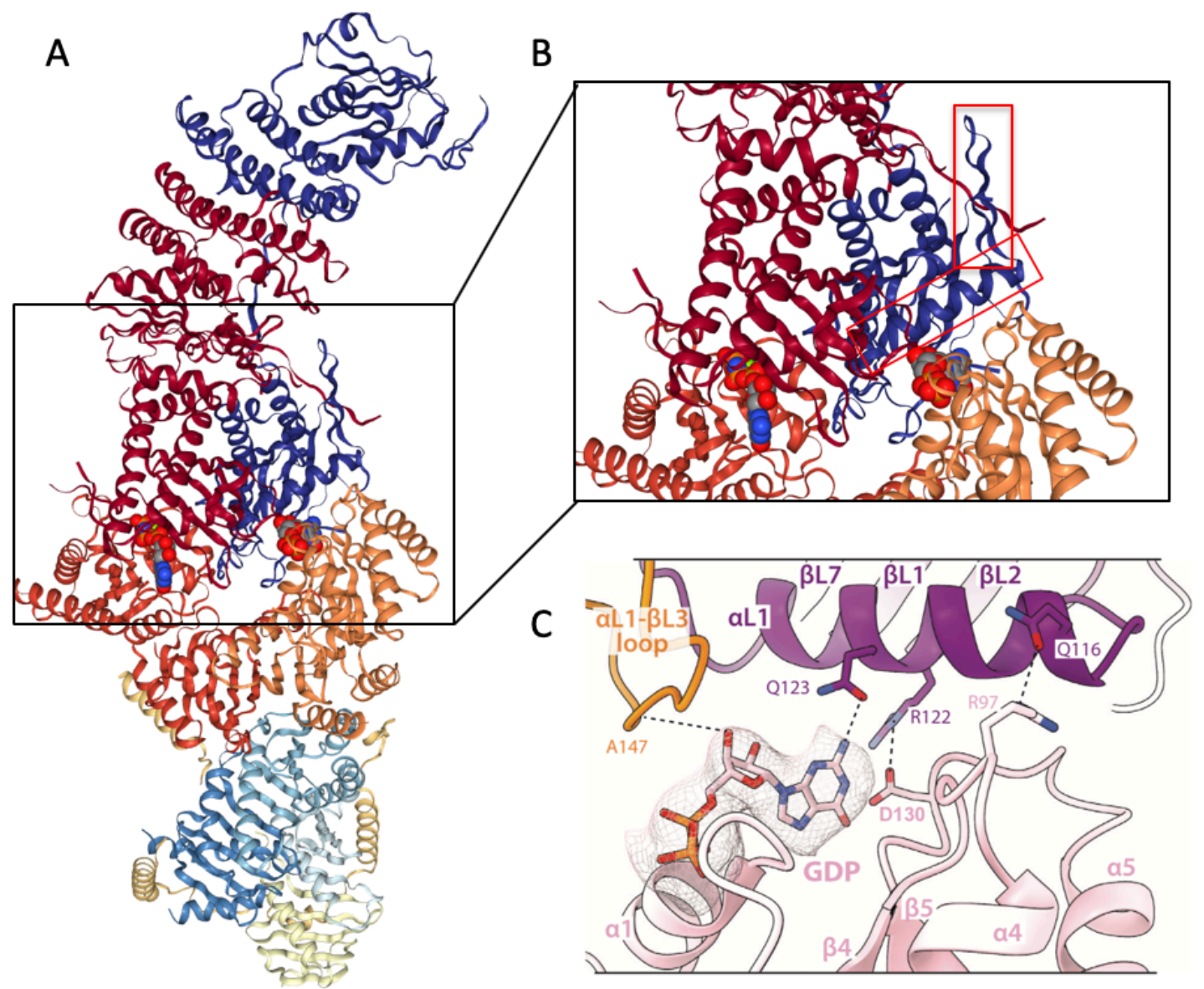

Figure 12: Cryo-EM structure of FLCN-FNIP2-Rag-Ragulator complex from Protein Data Bank 6ULG.

Proteins are indicated by the following colors: FLCN in dark blue, FNIP2 in dark red, RagA in orange, Rag C in light red. Other colors represent the components of the Ragulator pentamer. The nucleotides bound by RagA and C are indicated by the globes. $\mathbf{B}$ shows part of the whole structure (a) enlarged. The red brackets indicate the amino acids deleted by the patients' FLCN mutation delpG84-E132. The $\alpha$ L1 helix is deleted in the patients FLCN mutant protein. C shows Figure 3c from Shen et al. (2019) showing the interaction of the same $\alpha \mathrm{L} 1$ helix with the nucleotide binding domain of RagA. Here FLCN is shown in purple, RagA in pink and FNIP2 in orange. With kind permission of Cell Press.

Although regulators of the nucleotide loading state of both RagA/B and C/D which control mTORC1 activation have been identified, the upstream regulation of these processes, that are linked to the amino acid availability in the cells remain to some extent unknown. This could suggest, that the FLCN mutation does not lead to the inability of mTORC1 activation 
but rather enables its uncontrolled, constitutive activation, leading to oncogenic cell metabolism. Together with the structural findings of Shen et al. this shows a critical role, the $\mathrm{n}$-terminal region of FLCN holds making these mutations crucial for BHD disease.

So far, we cannot predict whether a specific FLCN mutation is tumorigenic. However, here we provide an in vivo assay that can be used to validate the tumorigenic effect a mutant protein withholds. Considering recent structural findings of the FLCN/FNIP2 complex the deleted protein section falls directly into a crucial $\alpha$ L1helix of the complex, regulating mTORC1 activation, again validating the driving force this mutation plays in tumorigenesis. In conclusion, these findings strongly suggest the investigation in how the loss of this function of FLCN might enable uncontrolled mTORC1 activity in tumor cells and could help in developing hypotheses as to how mTORC1 activation is linked to amino acid availability in the cell. A better understanding of what parts of the FLCN protein enable what function may lead to a prediction of the tumorigenic effect of FLCN mutations, improving therapy for BHD patients.

\subsection{Can specific target proteins be identified that bind to the small molecules generated by cell-based high throughput screen?}

\subsubsection{Generation of specific small molecule analogs that are substrates for click chemistry that maintain activity}

The development of a facile synthetic route of compound 76 (Wang et al. 2019) allowed for the synthesis of compound 83 that can be used in click chemistry and is still active in inhibition of HIF $2 \alpha$ translation. The ability to "click" compound 83 allows its isolation alongside interacting proteins from the cell lysate. Because the chemical reaction of the click chemistry produces a covalent bond between the substrates, we used the well-studied and easy to work with biotin-streptavidin interaction to try isolation of the compounds. This way, they can not only be stained as western blot using streptavidin HRP but also isolated using streptavidin coated beads.

Using this approach, we could identify a specific and reproducible pattern of protein bands binding to compound 83. Purification of the compound 83 and bound proteins complex required quite harsh conditions. That the complex survives suggests that the HIF2 $\alpha$ inhibitors form a strong bond with their target proteins. These findings do not exclude the possibility that the compounds form weaker bonds with other proteins that may be important in regulation of HIF $2 \alpha$ translation. Such targets will be missed in our current approach to identify direct targets and should be investigated in future experiments. 


\subsubsection{Development and optimization of pull-down techniques to purify candidate proteins}

A possible way to analyze proteins interacting with Compound 83 in a non-covalent way might be to click compound 83 to azide coated beads. The interacting proteins would then be bound to the beads via compound 83 as well. After separating the beads from the whole cell lysates, protein precipitation would then only separate the bound proteins while compound 83 and all proteins bound in a covalent way would stick to the beads. Analysis of the precipitated proteins could then reveal those proteins.

In order to analyze and identify the proteins that we could visualize in bands and that were bound covalently, compound 83 had to be isolated alongside them from the rest of the lysates of treated cells. Different approaches can be used to obtain this isolation.

For the first mass spectrometry analysis, we used beads coated with azide groups and performed the click reaction binding compound 83 directly and covalently to those beads. We hoped to ensure specificity of the isolation, because the click reaction is very specific. The downside of this approach is however that bound proteins can only be analyzed through mass spectrometry analysis after on-resin digestion. The click reaction cannot be reversed and the covalent bond between the azide groups of the beads and the alkyne groups of compounds 83 cannot be broken specifically. This makes it hard to optimize this method, also, because the only way to get results is through mass spectrometry analysis, which is a complicated technique, susceptible to small impurities. Therefore, identified proteins by mass spectrometry analysis cannot be confirmed by another analysis such as western blot using this same approach. However, this approach does not necessarily include protein precipitation which can allow analyzation of proteins interacting with compound 83 in a noncovalent way as mentioned above. This approach led to a list of 64

Another approach to isolating compound 83, was its biotinylation via click reaction following isolation using streptavidin coated beads. Using this method makes it easier to work with isolated proteins because the streptavidin-biotin interaction can easily be broken by protein precipitation and western blot analysis is possible. This gave us the opportunity of optimizing and repeating this approach without having to use mass spectrometry analysis to get results. However, it includes more steps and therefore holds more possibilities for errors. Using streptavidin coated beads, the click reaction is performed prior to isolation in contrast to using azide coated beads were the click reaction represents the isolation. One problem with this step was the protein precipitation after the click reaction and prior to the isolation through streptavidin coated beads that lead to unspecific protein background. Especially for identifying unknown proteins it is crucial to work very clean and have a specific procedure. However, with this approach further validation and optimization of the method was possible. For example, mass spectrometry results can be evaluated by western blot analysis. 


\subsubsection{Identification of candidate proteins that bind small molecule inhibitors}

Using the two different pull-down and purification techniques described above identified IRP1 was suggested to be a direct target protein of the compounds by western blot and mass spectrometry analysis. Previous studies with compound 76 showed through mobility shift assays that compound 76 enhanced the binding of IRP1 to an IRE of the HIF2 $\alpha$ mRNA (Zimmer et al. 2008). In addition, loss of IRP1 results in a translational derepression of HIF $2 \alpha$ mRNA (Anderson et al. 2014). Alongside IRP1, other ion sensing proteins (such as Staniocalcin-2 and Calpastatin) were detected by mass spectrometry. This led to our hypothesis that the compounds might bind to the ion sensing regions of these proteins. This would explain a possible way of how the compounds promote IRP1 binding to the IRE of HIF2 $\alpha$, possibly by replacing the iron molecule bound transiently in the iron-sulfur cluster of IRP1 thus enhancing its binding to mRNA.

Additionally, peflin was suggested as a direct target of the compounds by western blot analysis. peflin negatively regulates the vesicle transport from the endothelial reticulum to the Golgi apparatus by building a dimer with the apoptosis linked gene 2 (ALG-2). This dimer is disrupted when peflin binds to calcium (Rayl et al. 2016). In keeping with the earlier hypothesis, the compounds could interfere with calcium binding to peflin, therefore enhancing its negative effect on vesicle transport. Another hypothesis is that the compounds inhibit the building of the peflin and ALG-2 dimer, preventing its negative effect on vesicle transport. How this could play a role in HIF regulation and tumorigenesis still remains unclear.

Another interesting protein suggested as possible target of compound 83 was tumor susceptibility gene 101 (TSG101). Investigations on the role TSG101 plays in cancer progression has been controversial. While TSG101 was believed to be a tumor-suppressor protein once it was discovered ( $\mathrm{Li}$ and Cohen 1996), newer studies then revealed oncogenic properties of the protein in both prostate and breast cancer cells (Zhu et al. 2004). Additionally, upregulation of TSG 101 has been observed in different types of cancers such as papillary thyroid carcinoma (Liu et al. 2002), hepatocellular carcinoma (Shao et al. 2015) and lung cancer (Liu et al. 2010), to only name a few. Recently, Xu and Zheng (2019) also found higher expression levels of TSG101 in RCC. Additionally, they showed that downregulation of TSG101 in RCC cell lines A498 and 786-O inhibited cell proliferation through cell cycle arrest. If our compounds play a role in these pathways or if there is a connection to hypoxia signaling still remains unknown.

In conclusion my work led to the identification of candidate proteins targeted by the HIF $2 \alpha$ inhibitors. Further work is needed to validate these proteins as the direct targets and to functionally link them to HIF2 $\alpha$ translation and/or hypoxia sensing. There are different approaches to further validate candidate target proteins. One approach would be to reverse the isolation process. Compound 83 can be biotinylated again by click reaction after cell lysis 
of treated cells. Then, instead of targeting compound 83 for isolation, indicated target proteins can be isolated using immunoprecipitation. Western blot analysis could then again be stained with streptavidin HRP to see if the biotinylated compounds were isolated alongside the target protein. This would be another prove of the interaction of compound 83 with these proteins. Another possibility to see that the compounds' function depends on these proteins would be to knock them out and see if the compounds then lose their function of reducing HIF translation. Overall, my work lays the ground for using chemical biology to discover the mechanism(s) by which protein-targets of the compound regulate hypoxia signaling.

The work presented in this thesis is part of a larger team effort of the Iliopoulos lab and partner labs. Of course, planning all of the experiments was done with the help of Othon Iliopoulos and all other lab members. Meike Schneider taught me all the main procedures in the lab during the first month of my stay. All mass spectrometry analyses were done by other labs, as indicated in the methods section. 


\section{Summary}

Some familial cancer syndromes are known to cause renal cell carcinoma (RCC) in afflicted subjects. I studied the role of tumor suppressor genes in two syndromes: Birt-Hogg-Dubé (BHD) and von Hippel-Lindau (VHL). BHD is caused by a germline mutation of the tumor suppressor gene folliculin (FLCN). Patients are at risk of developing RCC throughout their lifetime.

In order to functionally classify the FLCN germ line mutations encountered during genetic testing, we established an in vivo assay, based on a mouse xenograft model. In this model, reintroduction of wildtype FLCN into FLCN-/- cells, when implanted into immunocompromised mice, showed a significant reduction of tumor growth compared to a comparable transfection of a non-functional exon 5 deletion. This particular FLCN deletion (FLCN p.Gly84_Glu132del) has been detected in a 14 year old patient with RCC of the left kidney.

Germ line mutations in the tumor suppressor von Hippel-Lindau (VHL) gene cause VHL disease, which can lead to the development of clear cell RCC. VHL is also mutated autosomal in the majority of sporadic clear cell RCC. Binding of the VHL protein to hypoxia inducible factors (HIF) leads to their degradation and subsequent suppression of tumor growth. Downregulation of the HIF2 $\alpha$ subunit is necessary and sufficient for tumor growth suppression and thus a promising target for cancer therapy.

Small molecules inhibiting translation of HIF2 $\alpha$ as chemical biology probes were used to identify proteins that regulate HIF expression and therefore may be involved in initiation and/or progression of RCC. We chemically modified the compounds to track their interaction with cellular protein-targets by incorporating an alkyne group in its structure. This compound (83), because of the alkyne group, can be isolated or marked with azide containing probes via click chemistry.

Compound 83 can be biotinylated with biotin-azide through a click reaction after cell lysis of treated VHL-/- cells. Proteins in these cell lysates bound in a strong way to compound 83 can be western blotted and made visible using streptavidin. This method showed a specific reproducible pattern of protein bands and ensured specificity. Using click chemistry, we performed two different isolation methods to later identify candidate proteins through mass spectrometry analysis. Among others, iron regulatory protein 1, peflin and Tumor susceptibility gene 101 were indicated as the most promising candidate target proteins by these methods. However, further experiments will have to be performed in order to evaluate these results.

Both FLCN and VHL play an important role in the development of renal cell carcinoma. The results presented here offer an assay to test FLCN mutations seen in BHD patients. Also, they give new insights into investigation of hypoxia signaling and its role in RCC. 


\section{Bibliography}

Aki D, Li Q, Li H, Liu YC, Lee JH (2018): Immune regulation by protein ubiquitination: roles of the E3 ligases VHL and Itch. Protein Cell 10, 395-404

Anderson SA, Nizzi CP, Chang YI, Deck KM, Schmidt PJ, Galy B, Damnernsawad A, Broman AT, Kendziorski C, Hentze MW (2014): The IRP1-HIF2 $\alpha$ axis coordinates iron and oxygen sensing with erythorpoiesis and iron absorption. Cell Metab $\underline{17}$, 282-290

Baba M, Hong SB, Sharma N, Warren MB, Nickerson ML, Iwamatsu A, Esposito D, Gillette WK, Hopkins III RF, Hartley JL (2006): Folliculin encoded by the BHD gene interacts with binding protein, FNIP1, and AMPK, and is involved in AMPK and mTOR signaling. Pro Natl Acad Sci U S A $\underline{103}$, 15552-15557

Benusiglio PR, Giraud S, Deveaux S, Méjean A, Correas JM, Joly D, Timsit MO, Ferlicot S, Verkarre V, Abadie C (2014): Renal cell tumour characteristics in patients with the BirtHogg-Dubé cancer susceptibility syndrome: a retrospective, multicentre study. Orphanet J Rare Dis $\underline{9}, 163$

Birt, AR, Hogg GR, Dubé WJ (1977): Hereditary multiple fibrofolliculomas with trochodiscomas and acrochordons. Arch Dermatol 113, 1674-1677

Cancer Genome Atlas Research Network (2013): Comprehensive molecular characterization of clear cell renal cell carcinoma. Nature $\underline{499}, 43-49$

Eng JK, McCormack AL, Yates JR (1994): An approach to correlate tandem mass spectral data of peptides with amino acid sequences in a protein database. J Am Soc Mass Spectrom $\underline{5}, 976-989$

Ferlay J, Colombet M, Soerjomataram I, Dyba T, Randi G, Bettio M, Gavin A, Visser O, Bray F (2018): Cancer incidence and mortality patterns in Europe: Estimates for 40 countries and 25 major cancers in 2018. Eur J Can 103, 356-387

Georgia Tech (2015): Click chemistry. Accessed on 03/24/2019. http://2015.igem.org/Team:GeorgiaTech/Background

Gordan JD, Bertovrt JA, Hu CJ, Diehl JA, Simon MC (2007): HIF-2 $\alpha$ promotes hypoxic cell proliferation by enhancing c-Myc transcriptional activity. Cancer Cell $\underline{11}$, 335-347

Guertin DA, Sabatini DM (2007): Defining the role of mTOR in cancer. Cancer Cell 12, 922

Hasumi H, Baba M, Hong SB, Hasumi Y, Huang Y, Yao M, Valera VA, Linehan WM, Schmidt LS (2008): Identification and characterization of a novel folliculin-interacting protein FNIP2. Gene $\underline{415}$, 60-67

Hasumi Y, Baba M, Ajima R, Hasumi H, Valera Va, Klein ME, Haines DC, Merino MJ, Hong SB, Yamaguchi TP (2009) Homozygous loss of BHD causes early embryonic lethality 
and kidney tumor development with activation of mTORC1 and mTORC2. Proc Natl Acad Sci U S A $\underline{106}$, 18722-18727

Iliopoulos O, Levy AP, Jiang C, Kaelin WG, Goldberg MA (1996): Negative regulation of hypoxia-inducible genes by the von Hippel-Lindau protein. Proc Natl Acad Sci U S A 23 , 10595-10599

Jensen DK, Villumsen A, Skytte AB, Gebauer Madsen M, Sommerlund M, Bendstrup E (2017): Birt-Hogg-Dubé syndrome: a case report and a review of the literature. Eur Clin Respir J 4, 1292378

Kim E, Goraksha-Hicks P, Li L, Neufeld TP, Guan KL (2008): Regulation of TORC1 by Rag GTPases in nutrient response. Nat Cell Biol 10, 935-945

Knudson AG (1971): Mutation and cancer: statistical study of retinoblastoma. Proc Natl Acad Sci U S A $\underline{68}, 820-823$

Kolb HC, Finn MG, Sharpless KB (2001): Click Chemistry: Diverse Chemical Function from a Few Good Reactions. Angew Chem Int Ed 40 (2001), 2004-2021

Kondo K, Klco J, Nakamura E, Lechpammer M, Kaelin WG (2002): Inhibition of HIF is necessary for tumor suppression by the von Hippel-Lindau protein. Cancer Cell 1 , 237-246

Laemmli UK (1970): Cleavage of structural proteins during the assembly of the head of bacteriophage T4. Nature 227, 680-685

Laviolette LA, Mermoud J, Calvo IA, Olson N, Boukhali M, Steinlein OK, Roider E, Sattler EC, Huang D, The BT (2017): Negative regulation of EGFR signaling by the human folliculin tumor suppressor protein. Nat Commun $\underline{8}, 15866$

Lawrence RE, Fromm SA, Fu Y, Yokom AL, Kim DJ, Thelen AM, Young LN, Lim CY, Samelson AJ, Hurley JH (2019): Structural mechanism of a Rag GTPase activation checkpoint by the lysosomal folliculin complex. Science 366, 971-977

Lay AJ, Jiang X, Kisker O, Flynn E, Underwood A, Condron R, Hogg PJ (2000): Phosphoglycerate kinase acts in tumour angiogenesis as a disulphide reductase. Nature $\underline{408}$, 869-873

Li L, Cohen SN (1996): tsg101: A novel tumor susceptibility gene isolated by controlled homozygous functional knockout of allelic loci in mammalian cells. Cell $\underline{85}$, 319-329

Lim DHK, Real PK, Nahorski MS, Macdonald F, Claessens T, Van Geel M, Gijezen L, Gille JJP, Giraud S, Richard S (2010): A new locus-specific (LSDB) for mutations in the folliculin (FLCN) gene. Hum Mutat 31, E1043-1051

Lindau A (1927): Zur Frage der Angiomatosis Retinae und ihrer Hirncomplikation. Acta Ophthalmol $\underline{4}, 193-226$ 
Lisztwan J, Imbert G, Wirbelauer C, Gstaiger M, Krek W (1999): The von Hippel-Lindau tumor suppressor protein is a component of an E3 ubiquitin-protein ligase activity. Genes Dev $\underline{13}, 1822-1833$

Liu T, Juang C, You H, Chou D, Hu CA, Chao F, Chen C, Cheng J (2002) Overexpression of tumor susceptibility gene TSG101 in human papillary thyroid carcinomas. Oncogene 21, $4830-4837$

Liu F, Yu Y, Jin Y, Fu S (2010) TSG101, identified by screening a cancer cDNA library and soft agar assay, promotes cell proliferation in human lung cancer. Mol Biol Rep $\underline{37}$, 28292838

Lubensky IA, Schmidt L, Zhuang Z, Weirich G, Pack S, Zambrano M, Walther MM, Choyke P, Linehan WM, Zbar B (1999): Hereditary and sporadic papillary renal carcinomas with cmet mutations share a distinct morphological phenotype. Am J Pathol 155, 517-526

Lyons J, Brubaker DK, Ghazi PC, Baldwin KR, Edwards A, Boukhali M, Strasser SD, Suarez-Lopez L, Lin, Y, Yajnik V (2018): Integrated in vivo multiomics analysis identifies p21-activated kinase signaling as a driver of colitis. Sci Signal 11, eaan3580

Majmundar AJ, Wong WJ, Simon MC (2010): Hypoxia inducible factors and the response to hypoxic stress. Mol Cell $\underline{40}$, 294-309

McAlistor GC, Nosinow DP, Jedrychowski MP, Wühr M, Huttlin EL, Erickson BK, Rad R, Haas W, Gygi SP (2014): MultiNotch MS3 enables accurate, sensitive, and multiplexed detection of differential expression across cancer cell line proteomes. Anal Chem $\underline{86}, 7150-$ 7158

McKusick VA, Amberger JS (1993): The morbid anatomy of the human genome: chromosomal location of mutations causing disease. J Med Genet $\underline{30}$, 1-26

Menko FH, Maher E, Schmidt LS, Middelton LA, Aittomäki K, Tomlinson I, Richard S, Linehan WM (2015): Hereditary leiomyomatosis and renal cell carcinoma (HLRCC). Renal cancer risk, surveillance and treatment. Fam Cancer 13, 637-644

Metelo AM, Noonan H, Li X, Jin Y, Baker R, Kamentsky L, Zhang Y, van Rooijen E, Shin J, Carpenter AE (2015): Pharmacological HIF2 $\alpha$ inhibition improves VHL diseaseassociated phenotypes in zebrafish model. J Clin Invest 125, 1987-1997

Motzer RJ, Bander NH, Nanus DM (1996): Renal-cell carcinoma. N Engl J Med $\underline{335}$, 865875

Muglia VF, Prando A (2015): Renal cell carcinoma: histological classification and correlation with imaging findings. Radiol Bras $\underline{48}, 166-174$

Nickerson ML, Warren MB, Toro JR, Matrosova V, Glenn G, Turner ML, Duray P, Merino M, Choyke P, Pavlovich CP (2002): Mutations in a novel gene lead to kidney tumors, lung 
wall defects, and benign tumors of the hair follicle in patients with the Birt-Hogg-Dubé syndrome. Cancer Cell $\underline{2}, 157-164$

Noonan HR, Metelo AM, Kamei CN, Peterson RT, Drummond IA, Iliopoulos O (2016): Loss of $v b l$ in the zebrafish pronephros recapitulates early stages of human clear cell renal cell carcinoma. Dis Models Mech $\underline{9}, 873-884$

Pavlovich CP, McClellan WM, Eyler RA, Hewitt SM, Zbar B, Linehan WM, Merino MJ (2002): Renal tumors in the Birt-Hogg-Dubé syndrome. Am J Surg Pathol 26, 1542-1552

Petit CS, Roczniak-Ferguson A, Fergusan SM (2013): Recruitment of folliculin to lysosomes supports the amino acid-dependent activation of Rag GTPases. J Cell Biol 202, 1107-1122

Pichler R, Heidegger I (2017): Novel concepts of antiangiogenic therapies in metastatic renal cell cancer. Memo $\underline{10}, 206-212$

Protein Data Bank: RCSB PDB - 6ULG. Cryo-EM structure of the FLCN-FNIP2-RagRagulator complex. Accessed on 01/04/2020. https://www.rcsb.org/3d-view/6ULG

Rayl M, Truitt M, Held, A, Sargeant J, Thorsen K, Jay JC (2016): Penta-EF-Hand protein peflin is a negative regulator of ER-to-golgi transport. PloS one $\underline{11}$, e0157227

Sanchez M, Galy, B, Muckenthaler MU, Hentze MW (2007): Iron-regulatory proteins limit hypoxia-inducible factor- $2 \alpha$ expression in iron deficiency. Nat Struct Mol Biol 14, 420-426

Schmidt LS, Linehan WM (2016): Genetic predisposition to kidney cancer. Semin oncol $\underline{43}$, 566-574

Schmidt LS, Linehan WM (2018): FLCN: The causative gene for Birt-Hogg-Dubé syndrome. Gene $\underline{640}, 28-42$

Schneider M, Dinkelborg K, Xiao X, Chan-Smutko G, Hruska K, Huang D, Sagar P, Harisinghani M, Iliopoulos O (2018): Early onset renal cell carcinoma in an adolescent girl with germline FLCN exon 5 deletion. Fam Cancer 17, 135-139

Schödel J, Oikonomopoulos S, Ragoussis J, Pugh CW, Ratcliffe PJ, Mole DR (2011): Highresolution genome-wide mapping of HIF-binding sites by ChIP-seq. Blood 117, 207-217

Schödel J, Grampp S, Maher ER, Moch H, Ratcliffe PJ, Russo P, Mole DR (2016): Hypoxia, hypoxia-inducible transcription factors, and renal cancer. Eur Urol $\underline{69}$, 646-657

Shao Z, Ji W, Liu A, Qin A, Shen L, Li G, Zhou Y, Hu X, Yu E, Jin G (2015): TSG101 silencing suppresses hepatocellular carcinoma cell growth by inducing cell cycle arrest and autophagic cell death. Med Sci Mon 21, 3371-3379

Shen C, Beroukhim R, Schumacher SE, Zhou J, Chang M, Signoretti S, Kaelin WG (2011): Genetic and functional studies implicate HIF1 $\alpha$ as a $14 \mathrm{q}$ kidney cancer suppressor gene. Cancer Discov 1 , 222-235 
Shen K, Rogala KB, Chou HT, Huang RK, Yu Z, Sabatini DM (2019) Cryo-EM structure of the human FLCN-FNIP2-Rag-Ragulator complex. Cell 179, 1319-1329

Shuch B, Amin A, Armstrong A, Eble J, Ficarra V, Lopez-Beltran A, Martignoni G, Rini B, Kutikov A (2015): Understanding pathologic variants of renal cell carcinoma: distilling therapeutic opportunities from biologic complexity. Eur Urol 67, 85-97

Siegel RL, Miller KD, Jemal A (2019): Cancer statistics, 2019. CA Cancer J Clin 69, 7-34.

Stamatakis L, Metwalli AR, Middelton LA, Linehan WM (2013): Diagnosis and management of BHD-associated kidney cancer. Fam Cancer 12, 397-402

Toro JR, Wei MH, Glenn GM, Weinreich M, Toure O, Vocke C, Turner M, Choyke P, Merino MJ, Pinto PA (2008): BHD mutations, clinical and molecular genetic investigations of Birt-Hogg-Dubé syndrome: a new series of 50 families and a review of published reports. J Med Genet 노, 321-331

Tsun ZY, Bar-Peled L, Chantranupong L, Zoncu R, Wang T, Kim C, Spooner E, Sabatini DM (2013): The folliculin tumor suppressor is a GAP for RagC/D GTPases that signal amino acid levels to mTORC1. Mol Cell $\underline{52}, 495-505$

Vocke CD, Yang Y, Pavlovich CP, Schmidt LS, Nickerson ML, Torres-Cabala CA, Merino MJ, McClellan MW, Zbar B, Linehan WM (2005): High frequency of somatic frameshift BHD gene mutations in Birt-Hogg-Dubé-associated renal tumors. JNCI 97, 931-935

Von Hippel E (1904): Ueber eine sehr seltene Erkrankung der Netzhaut. Arch Ophthal $\underline{95}$, 83-106

Wang X, Ahn J, Fiejtek DK, Lin L, Dinkelborg K, Sundaram R, Zheng S, Iliopoulos O, Hodgetts KJ (2019): Synthesis of the HIF-2 $\alpha$ translation inhibitor compound 76 via a JappKlingemann coupling. Tetrahedron Lett $\underline{60}$, 983-985

Xu C, Zheng J (2019): siRNA against TSG101 reduces proliferation and induces G0/G1 arrest in renal cell carcinoma - involvement of c-myc, cyclin E1, and CDK2. Cell Mol Biol Lett 24,7

Zhu G, Gilchrist R, Borley N, Ching HW, Morgan M, Marshall JF, Camplejohn RS, Muir GH, Hart IR (2004): Reduction of TSG101 protein has negative impact on tumor cell growth. In J Cancer 109, 541-547

Zimmer M, Doucette D, Siddiqui N, Iliopoulos O (2004): Inhibition of hypoxia-inducible factor is sufficient for growth suppression of VHL-/- tumors. Mol Cancer Res $\underline{2}$, 89-95

Zimmer M, Ebert BL, Neil C, Brenner K, Papaioannou I, Melas A, Tolliday N, Lamb J, Pantopoulos K, Golub T (2008): Small-molecule inhibitors of HIF-2a translation link its 5'UTR iron-responsive element (IRE) to oxygen sensing. Mol Cell $\underline{32}, 838-848$ 


\section{Note of thanks}

First, I want to thank Professor Matthias Dobbelstein of the University of Göttingen for supporting me right from the start and encouraging me to pursue my plan to conduct research in Boston. He has continued to support me through the whole process and always took the time to help me in finishing this thesis. I am grateful to Professor Dörthe Katschinski of the University of Göttingen for agreeing to support my thesis as cosupervisor. The Boehringer Ingelheim Fonds MD stipend program was instrumental in supporting my stay in Boston but also introduced me to a wide network of researchers and exciting meetings with other BIF alumni. I want to thank Professor Othon Iliopoulos of the MGH Center for Cancer Research for giving me the opportunity to work in his lab for a year and supporting me in every way he could. Doctor Meike Schneider introduced me to the lab. I am grateful for her intensive training when I started in the lab. Thanks to all the other lab members of the Iliopoulos laboratory at that time for a number of explanations and ideas helping me during my stay there. Lastly, I want to thank Doctor Andrew Stephens in helping me put my research into writing and assisting in literature research to put my work in contrast with the newest publications. 